\title{
Chapter 14 \\ Siderophores and their Applications in Wood, Textile, and Paper Conservation
}

\author{
Stavroula Rapti, Stamatis C. Boyatzis, Shayne Rivers, and \\ Anastasia Pournou
}

\begin{abstract}
Since the 1950s, siderophores have been acknowledged as nature's chelating powerhouse and have been given considerable attention concerning their crucial roles in microorganisms and plants for capturing non-bioavailable iron from aquatic and terrestrial environments, as well as for their applications in agriculture, health, and materials science and environmental research. In recent years, the exceptional affinity and complexing efficacy, as well as the high selectivity of these potent chelators towards iron(III), have led to investigations by researchers aiming at understanding their capacity for removing potentially harmful and aesthetically unacceptable iron stains from organic substrates in cultural heritage objects. In the context of the conservation of cultural heritage objects, potent chelators have been proposed to remove iron from surfaces by transferring it to the more soluble complexed phase. In this review, the origins and the types of bio-environments of siderophores as well as their structure and chemistry are investigated and related to the requirements of conservation. It is evident that, given the enormous potential that these chelators have, the research for their application in cultural heritage is at a preliminary level, and has to date been within the rather narrow context of cellulosic materials such as paper and wood. The results of research conducted to date are presented in this review and questions regarding the optimal use of siderophores as iron-removing agents are posed.
\end{abstract}

Keywords Siderophores · Green chelators · EDTA (ethylene-diamino tetra-acetic acid) - DTPA (diethylene-triaminopenta-acetic or pentetic acid) - Cultural heritage · Conservation

S. Rapti · S. C. Boyatzis $(\bowtie) \cdot$ A. Pournou

Department of Conservation of Antiquities and Works of Art, University of West Attica, Athens, Greece

e-mail: srapti@uniwa.gr; sboyatzis@uniwa.gr; pournoua@uniwa.gr

S. Rivers

West Dean College of Arts and Conservation, Chichester, West Sussex, UK

(C) The Author(s) 2021

E. Joseph (ed.), Microorganisms in the Deterioration and Preservation of Cultural

Heritage, https://doi.org/10.1007/978-3-030-69411-1_14 


\section{Introduction}

Siderophores are among nature's successful solutions to overcome the challenges of bioavailable iron in aqueous systems (Barton and Hemming 1993; Neilands 1995; Boukhalfa and Crumbliss 2002; Crichton 2019).

The origin of the word siderophore is Greek and means an "iron carrier" (Neilands 1995; Saha et al. 2013); siderophores are natural metal-chelating agents, employed by a wide range of microorganisms and plants to mobilize iron from its least available sources (Höfte 1993; Neilands 1995; Kraemer 2004; Ali and Vidhale 2013).

They are secondary metabolites of low molecular masses (200-2000 Da) and high affinity for iron $\left(K_{f}>10^{30}\right)$ (Hider and Kong 2010; Saha et al. 2013; Wang et al. 2014; Ahmed and Holmström 2014; Khan et al. 2018).

Siderophores have been classified depending on the oxygen ligands for Fe(III) coordination, as catecholate (sensu stricto, catecholates, and phenolates; better termed as aryl caps), hydroxamate, carboxylate, and mixed types (Miethke and Marahiel 2007; Ahmed and Holmström 2014; Saha et al. 2016; Khan et al. 2018). More than 500 different types of siderophores are known, of which 270 have been structurally characterized (Hider and Kong 2010; Ali and Vidhale 2013; Wang et al. 2014; Ahmed and Holmström 2014).

They have a high biotechnological potential and a wide range of applications not only in ecology, agriculture, and medicine but also in the field of conservation of cultural heritage, mostly for removing iron corrosion products from artifacts (Albelda-Berenguer et al. 2019).

The question of removing iron from organic substrates of cultural heritage has been previously considered through the use of chelators such as citric acid, EDTA (ethylene-diaminetetraacetic acid), DTPA (diethylene-triaminepenta-acetic, or pentetic acid), etc. (Almkvist et al. 2005; Burgess 1991; Margariti 2003; Rivers and Ummey 2003; Richards et al. 2012). Water-soluble iron(III) ions are highly reactive, as they participate in Fenton-type reactions (see Sect. 14.4.1) (Koppenol 1993; Kolar and Strlic 2001; Bulska and Wagner 2002; Dunford 2002; Burkitt 2003; Jablonský et al. 2010; Corregidor et al. 2019) causing severe oxidative stress to organic substrates.

The removal of iron stains from wood, textiles, and paper substrates emerges as an important issue, which although it has been typically dealt by the abovementioned chelators, these were shown to not fully encompass iron(III) in their complexes, and significantly, not to prevent the harmful oxidative stress on cellulosic materials (Kolar 1997; Kolar and Strlič 2004). In addition, these complexing media do not offer the best possible solution due to a lack of specificity. EDTA, for instance, complexes similarly iron, copper, manganese, cobalt, and other cultural heritage-significant ions and unwanted side-reactions (see below) which in the case of siderophores are avoided. Therefore the need for increased specificity from chelators has been recognized in the field of cultural heritage and efforts employing siderophores have been reported among some research groups (Wagner and Bulska 
2003; Rapti et al. 2017; Albelda-Berenguer et al. 2019). In this review, these efforts and their results will be presented along with the questions that still need to be answered.

The enormous biodiversity among bacteria, fungi, and particular types of plants has led to optimized strategies for sequestering abundant, but minimally bioavailable iron from the environment by employing a vast palette of chelating agents, commonly termed as siderophores. This highly successful strategy can only be seen as a triumph of nature which produces custom-made iron chelators according to the types of organisms, the character of the environment itself, and the severity of the iron nutrient demand. Learning from nature can teach us the right approach under the right condition for our applications, including conservation. Within this review, this leads to the necessity for presenting siderophores, their biological origins, the structures, and their chemistry as a necessary background (Sects. 14.1-14.3) for effectively considering their applications in conservation regarding the removal of unwanted iron from certain types of materials (Sect. 14.4).

\section{Biosynthesis, Roles, and Applications of Siderophores}

Almost all microorganisms and living members of the animal and plant kingdom are dependent on iron (Renshaw et al. 2002; Hider and Kong 2010; Saha et al. 2013; Ahmed and Holmström 2014; Khan et al. 2018).

Iron's unique chemical properties, such as its ability to coordinate and activate oxygen and its ideal redox chemistry $\left(\mathrm{Fe}^{2+}, \mathrm{Fe}^{3+}, \mathrm{Fe}^{5+}\right)$, turn this element into an essential and vital nutrient of the growth and developmental processes of every living organism (Saha et al. 2013, 2016; Ahmed and Holmström 2014; Khan et al. 2018), because it is acting as a catalyst in enzymatic processes, oxygen metabolism, electron transfer, and DNA and RNA syntheses (Hider and Kong 2010; Ahmed and Holmström 2014; Saha et al. 2016).

Although iron is abundant in nature, it is not easily bioavailable because at neutral $\mathrm{pH}$ and in the presence of atmospheric oxygen it undergoes rapid oxidation from ferrous $\left(\mathrm{Fe}^{2+}\right)$ to ferric $\left(\mathrm{Fe}^{3+}\right)$ iron and finally forms insoluble ferric hydroxides and oxy-hydroxide, which is almost unavailable for acquisition by organisms (Renshaw et al. 2002; Saha et al. 2013; Wang et al. 2014). More specifically, the solubility and consequently the bioavailability of iron as ferric oxy-hydroxide are less than $10^{-18} \mathrm{M}$, while microbes require $10^{-5}-10^{-8} \mathrm{M}$ for carrying out vital physiological and metabolic processes and have optimal growth (Saha et al. 2013; Wang et al. 2014; Khan et al. 2018).

To solve this problem, a vast number of bacteria, fungi, plants, and even higher eukaryotes under iron-deficient conditions produce siderophores, which is an essential metabolic feature that allows them to survive (Renshaw et al. 2002; Saha et al. 2013, 2016; Ahmed and Holmström 2014; Khan et al. 2018).

Hydroxamate types of siderophores comprise the most common group of siderophores found in nature and are produced by both bacteria and fungi (Ali and 
Vidhale 2013; Saha et al. 2016; Khan et al. 2018). Catecholate siderophores are found only in certain bacteria (Ali and Vidhale 2013; Saha et al. 2016; Khan et al. 2018), while the carboxylate type is produced by few bacteria such as Rhizobium and Staphylococcus and fungi such as Mucorales belonging to the phylum Zygomycota (Saha et al. 2016; Khan et al. 2018).

\subsection{Biosynthesis}

Siderophore biosynthesis is typically regulated by iron levels of the environment where the organism lives (Hider and Kong 2010). Although iron deficiency is the key factor, other external factors such as $\mathrm{pH}$, temperature, carbon source, and the presence of other metals play an important role (Saha et al. 2013). Thus some hydroxamate siderophores are prevalent in lower or acidic $\mathrm{pH}$, whereas other catecholate siderophores are produced in neutral to alkaline pH (Saha et al. 2013). The distinction of the various siderophore types and their significance regarding applications in conservation can be found in Sect. 14.3.2.

There are two biosynthesis pathways involved in siderophores' synthesis (a) the dependent on non-ribosomal peptide synthetases (NRPSs) and (b) the independent of NRPS (Miethke and Marahiel 2007; Saha et al. 2013; Khan et al. 2018). The non-ribosomal peptide synthetases are large multi-enzyme complexes responsible for the synthesis of several biologically important peptidic products without an RNA template (Miethke and Marahiel 2007; Saha et al. 2013). In general, NRPSs are essentially assembly lines of specialized domains that link amino acids via thioester intermediates. They function in a similar manner to that of fatty acid synthetase (Hider and Kong 2010). They consist of three domains required for peptide bond formation (a) adenylation domain, (b) peptidyl carrier protein domain (PCP or thiolation), and (c) condensation domain, responsible for the assembly of a wide array of amino, carboxy, and hydroxy acids in various combinations to produce macrocyclic peptidic with high structural variability (Miethke and Marahiel 2007; Hider and Kong 2010; Saha et al. 2013).

NRPSs are responsible mainly for the synthesis of aryl-capped siderophores (Miethke and Marahiel 2007). Hydroxamate and carboxylate siderophores are assembled by NRPS-independent mechanisms in the majority of cases, even though in some cases, NRPSs are partially involved in the synthesis of hydroxamate and carboxylate siderophores to build a peptidic backbone to which the ironcoordinating residues are attached (Miethke and Marahiel 2007).

Nonetheless, organisms such as bacteria, fungi, and plants have different ways to synthesize their siderophores (Khan et al. 2018; Albelda-Berenguer et al. 2019) and therefore the siderophores can be categorized based on the organism that produces them: fungal, bacterial, plant (phytosiderophores), cyanobacterial, or mammalian siderophores (Khan et al. 2018). 


\subsection{Roles}

Fungal siderophores are mainly of hydroxamate type, belonging to the ferrichrome family (i.e., ferrichrome A), coprogen and triacetylfusarinine families, and carboxylate type of siderophores (Renshaw et al. 2002; Hider and Kong 2010; Ahmed and Holmström 2014; Khan et al. 2018). Aspergillus fumigatus and Aspergillus nidulans have been thoroughly studied for their siderophore production (Khan et al. 2018).

Bacterial siderophores comprise extracellular forms of siderophore (Khan et al. 2018). Most of the bacterial siderophores are catecholates (i.e., enterobactin), while there are also some carboxylates (i.e., rhizobactin), hydroxamates (i.e., ferrioxamine B), and mixed types (i.e., pyoverdine) (Ahmed and Holmström 2014). The Gramnegative, facultative anaerobe Escherichia coli, found normally in the intestine, is the most widely studied bacterium for siderophore production. It principally produces enterobactin, with the highest affinity towards iron(III) ion, of any known siderophore (Khan et al. 2018). Members of Actinobacteria such as Streptomyces are also well-recognized for their ability to produce multiple siderophores such as the characteristic desferrioxamines G, B, and E (Wang et al. 2014).

Mammalian siderophores may have structural and functional similarity to bacterial siderophores (Khan et al. 2018). Studies have confirmed the existence of a mammalian siderophore and provided insight into its structure, biosynthesis, and function (Devireddy et al. 2010). Siderocalin is the only mammalian siderophorebinding protein currently known however, compounds that serve endogenously as siderophore equivalents have been identified and characterized through associations with siderocalin (Correnti and Strong 2012).

Marine organisms such as phytoplankton and cyanobacteria can also produce siderophores (Ahmed and Holmström 2014). Cyanobacterial siderophores are mainly of dihydroxamate-type (such as schizokinen and anachelin H) (Khan et al. 2018). Moreover, the coastal marine cyanobacterium Synechococcus sp. produces three amphiphilic siderophores, synechobactins A, B, and C (Ito and Butler 2005).

Finally, plant siderophores (phytosiderophores) are hexadentate ligands that coordinate $\mathrm{Fe}(\mathrm{III})$ with their amino and carboxyl groups (Ahmed and Holmström 2014). These are prevalent in members of Poaceae and belong to the mugineic acid family that form a hexadentate Fe-phytosiderophore complex (Kumar et al. 2016; Khan et al. 2018). Mugineic acid has been found to be a much better complexing agent for the ferrous ion than ligands which contain hydroxamate or catecholate (Sugiura and Nomoto 1984).

Under low iron availability, which is a critical growth-limiting factor for virtually all aerobic microorganisms, siderophores become important in several ecological niches. These are included in four major habitats: soil and surface water, marine water, plant tissue (pathogens), and animal tissue (pathogens) (Hider and Kong 2010). Therefore, mixtures of siderophores control the supply of iron in critical environments such as rivers, marine surface water, forest soils and agricultural land and pathogenic bacteria and fungi employ siderophores in a chemical competition with their plant and animal hosts (Hider and Kong 2010). 
The primary role of siderophores is to chelate the ferric iron from different terrestrial and aquatic habitats and make it available for microbial and plant cells (Ahmed and Holmström 2014). Thus, they exhibit growth factor activity for nearly all known fungi and plants (Renshaw et al. 2002; Ahmed and Holmström 2014). Additionally, many siderophores have several significant roles, such as virulence in pathogens, oxidative stress tolerance, and antimicrobial properties (Renshaw et al. 2002; Khan et al. 2018).

Several studies have demonstrated the role of siderophores in mediating pathogen multiplication and development of virulence, because iron is critical for many pathogenic species (Neilands 1995; Saha et al. 2013). Moreover, siderophores have been extensively reported to reduce oxidative stress in microorganisms producing them (Khan et al. 2018). Another important role of siderophores is their contribution in biofilm formation: studies have shown that intracellular iron concentration plays an important role in the development of the complex community of microorganisms growing in various substrates in an aqueous environment (Saha et al. 2013).

Nonetheless, apart from their primary role in iron chelation and mobilization, siderophores have the ability to bind a variety of other heavy metals such as $\mathrm{Al}^{3+}$, $\mathrm{Zn}^{2+}, \mathrm{Cu}^{2+}, \mathrm{Pb}^{2+}$, and $\mathrm{Cd}^{2+}$ (Saha et al. 2013; Ahmed and Holmström 2014; Kumar et al. 2016; Złoch et al. 2016; Khan et al. 2018). Thus, siderophores are also seen serving in bioremediation for cadmium and lead toxicity (Khan et al. 2018) and can affect homeostasis and heavy metal tolerance of microorganisms (Złoch et al. 2016). This is the reason why siderophore-producing bacteria have been used to assist in phytoremediation of heavy metals from contaminated environments or in the scarcity of nutrients (Saha et al. 2013; Thiem et al. 2018).

It becomes thus apparent why siderophores have wide applications in various fields such as agriculture, medicine, ecology, and environmental applications (Ali and Vidhale 2013; Saha et al. 2016).

\subsection{Applications}

In agriculture, siderophores can be considered to be an eco-friendly alternative to hazardous chemical pesticides as they can play a significant role in the biological control mechanism against certain phytopathogens. Moreover, they can promote plant growth as iron is required for chlorophyll biosynthesis, redox reactions, and some important physiological activities in plants (Saha et al. 2016).

Medical siderophores have been exploited to deliver drugs inside the cells, a concept adopted from the naturally occurring sideromycins (daunomycins, albomycins, microsins) (Saha et al. 2013). Sideromycins are conjugates of siderophores and antibiotics, in which the antibiotic utilizes siderophores as mediators to enter the cells via the iron-uptake machinery. This process is known as the Trojan horse strategy (Ali and Vidhale 2013; Saha et al. 2013, 2016; Khan et al. 2018). They can be also used to treat diseases caused by pathogenic microorganisms 
by exploiting their antimicrobial property (Khan et al. 2018). Moreover, medical siderophores have been used to treat iron overload conditions such as B-thalassemia and aluminum overload (Renshaw et al. 2002; Ali and Vidhale 2013; Saha et al. 2016; Khan et al. 2018). Desferrioxamine and other hydroxamate siderophores have also been studied for use in the treatment of other medical conditions, including cancer, infectious diseases such as malaria, due to their antimicrobial properties and for decontamination by actinides such as neptunium and plutonium (Renshaw et al. 2002; Saha et al. 2016; Khan et al. 2018).

The ability of siderophores to complex actinides, which result mainly by the production and testing of weapons and by nuclear power stations and reprocessing plants, indicates their use for reprocessing of nuclear fuel, bioremediation of metal-contaminated sites, and the treatment of industrial waste, including radioactive waste (Renshaw et al. 2002; Saha et al. 2016; Khan et al. 2018).

Another application of siderophores is in the field of microbial ecology as it has been demonstrated that a siderophore-based approach has markedly facilitated the growth and cultivation in the pure culture of many unculturable organisms (Saha et al. 2016).

Finally, some siderophores have been characterized to function as sensitive, robust, and specific $\mathrm{Fe}^{3+}$ biosensors. Nonetheless, most of them have not yet been characterized and thus it could be just hypothesized that some of them may also turn out to be novel and potential biosensors (Saha et al. 2016).

Besides significant ecological agricultural, environmental, medical, and biotechnological applications, siderophores have recently found a new field for applications in the conservation of cultural heritage, and in particular, paper and wood (AlbeldaBerenguer et al. 2019), which will be thoroughly discussed in a following section.

\section{The Structure and Chemistry of Siderophores}

\subsection{Chelation of Iron}

Exceptionally stable complexes can be formed between metal ions such as iron(III) and multidentate organic Lewis bases, called chelators (from the Greek " $\chi \eta \lambda \dot{\eta}$," meaning hoof or claw, suggesting two-sided, or bidentate gripping ability). Chelators are capable for two-, four-, or six-sided coordination, accordingly termed as bi-, tetra-, or hexadentate ligands, respectively (Cotton et al. 1995; Crichton 2019). This way, highly stable multidentate coordination complexes are formed.

Two forms of iron are the most common in the environment: (a) ferric or iron(III) (in its ionic form it is depicted as $\mathrm{Fe}^{3+}$ ) which is the most abundant and (b) ferrous or iron(II) which is the least stable, often oxidizable to ferric compounds. The former is mostly the case in the discussion within this paper as it is the main species in iron corrosion products and therefore a usual target for conservators. The two forms of iron are in a dynamic relationship between each other depending on factors such as the presence of oxygen, the $\mathrm{pH}$, complexing agents, the solubility of their 
compounds, etc. Excellent books and reviews are available for further reading (Cornell and Schwertmann 2003; Crichton 2019). The reader also needs to have an adequate background on the acid and base character and their inter-relations, as well as the significance of $\mathrm{pH}$ with respect to the acidity constant of an acid; these are key to understand the siderophore action, and more generally, chelation (see for instance, Harris 2015).

Ferric ion $\left(\mathrm{Fe}^{3+}\right)$ is a Lewis acid capable of accepting an electron pair from functional groups in chelators, which on their part act as Lewis bases; the latter can be electron pair-rich groups such as hydroxyl $(: \mathrm{OH})$, hydroxide $\left(: \mathrm{OH}^{-}\right)$, and amino $\left(: \mathrm{NH}_{2}\right)$ groups (Cotton et al. 1995; Marusak et al. 2006; Harris 2015; Crichton 2019). The coordination of metals by organic or inorganic molecules is a ubiquitous phenomenon in nature. For instance, metal ions, such as $\mathrm{Fe}^{3+}{ }_{(\mathrm{aq})}$, can be coordinated in aqueous solutions by six water molecules arranged according to octahedral geometry; in these, the electron-rich oxygen atom in each water molecule behaves as the Lewis acid. The coordination process occurs stepwise involving ligand molecules (such as $\mathrm{H}_{2} \mathrm{O}$ ) in a sequential manner, so that most $\mathrm{Fe}^{3+}$ ions in their aqueous solutions exist as the hexa-aquo complex. Equation (14.1) shows the overall reaction for the complexation of $\mathrm{Fe}^{3+}$ by water in the formation of the iron hexa-aquo complex. This complex behaves as an acid as it further interacts with water and reduces the $\mathrm{pH}$ of the solutions; with $\mathrm{pKa}$ value 2.2 , a $0.1 \mathrm{M}$ aqueous iron(III) solution, assumed to be entirely in is hexa-aquo complex form, is expected to show a $\mathrm{pH}$ as low as 1.6.

$$
\underset{\text { ferric ion }}{\mathrm{Fe}^{3+}}+6 \mathrm{H}_{2} \mathrm{O} \rightleftharpoons \underset{\text { hexa-aquo complex }}{\mathrm{Fe}\left(\mathrm{H}_{2} \mathrm{O}\right)_{6}{ }^{3+}} \beta=\mathrm{K}_{\mathrm{f}}=\frac{\left[\mathrm{Fe}\left(\mathrm{H}_{2} \mathrm{O}\right)_{6}\right]^{3+}}{\left[\mathrm{Fe}^{3+}\right]}
$$

A chelate complex forms as a ligand that approaches the ferric ion $\left(\mathrm{Fe}^{3+}\right)$ and arranges in its first coordination sphere; a stable hexacoordinate complex is thus formed, in which properties such as solubility, hydrolysis, and reduction are utterly controlled (Dhungana and Crumbliss 2005; Pepper and Gentry 2015; AlbeldaBerenguer et al. 2019).

The overall process is governed by the combination of enthalpy and entropy factors and characterized by an equilibrium constant, which is called the stability constant often symbolized as $\log \beta$; the higher the value of $\log \beta$, the more stable is the coordination complex (Nakamoto 2009; Harris 2015; Crichton 2019).

The chelate complexes of ferrous ions $\left(\mathrm{Fe}^{2+}\right)$ are much less stable with stabilities more than ten orders of magnitude lower than those of iron(III). As a result, the reduction of iron(III) to iron(II) has enormous implications on the dechelation (or release) mechanisms of uptaken iron inside the living systems and is also a significant factor that needs to be taken into account in the various applications of siderophores (Boukhalfa et al. 2006; Hider and Kong 2010; Albelda-Berenguer et al. 2019). 
The hard-soft acid base (HSAB) concept proposed by Pearson further helps to evaluate and understand the high tendency for reaction between Lewis acids and bases of similar hardness (Cotton et al. 1995; Marusak et al. 2006; Harris 2015; Crichton 2019). As a result, chelators having a hard base character can complex iron (III) (a hard acid) so efficiently that the latter can be removed from its insoluble and minimally bioavailable iron oxides, hydroxy-oxides, and hydroxide. Siderophores possess such ability, which has been developed as one of nature's successful strategies to sequester iron (Bauer and Exner 1974; Agrawal 1979; Boukhalfa and Crumbliss 2002; Kraemer 2004; Tseng et al. 2006; Reichard et al. 2007; Hider and Kong 2010; Sharpe et al. 2011; Ahmed and Holmström 2014; Albelda-Berenguer et al. 2019). In conservation, a similar issue needs to be addressed: potent chelators can be employed to remove iron from surfaces of cultural heritage objects by transferring it to the more soluble complexed phase; this way, a cleaning effect can be achieved.

An addition, most iron(III) chelate complexes are colored due to specific electron transitions facilitated by charge transfer between the iron(III) and the ligand. This offers an extra asset for visual observation, and additionally, a widely followed methodology for titrating of such complexes (Boukhalfa et al. 2006; Harris 2015).

\subsection{The Tool: Siderophores}

Siderophores have been developed by living systems based on organic functional groups (phenolic hydroxyls, carboxyl groups, hydroxamic and sulfhydryl groups) capable of efficient complexation of metals. Their development is also based on the number and the stereochemical arrangement that these groups possess for more efficient complexation in order to overcome the limited bioavailability of iron as a micronutrient (Kraemer 2004; Kalinowski and Richardson 2005; Bertrand et al. 2009; Hider and Kong 2010).

Siderophores, as most chelators, form thermodynamically stable hexacoordinate complexes with iron(III) accommodated in the most favorable molecular geometry (see, for instance, Fig. 14.1b) (Crumbliss 1990; Kraemer 2004); this along with the high affinity of siderophores for iron(III) produce strong driving forces towards complexation. The stability constants for iron(III) are generally higher than iron (II) which means that ferric complexes are generally much easier to form as compared to ferrous. This preference is more significant in the case of siderophores, as compared to other chelators such as EDTA. This accordingly plays a major role in stability of ferric complexes (see Sect. 14.3.3.3); in the context of conservation applications, it has the significance that in the presence of the wrong chelator, or even more, in the absence of any chelator, ferric ions can be reduced to ferrous with detrimental effects on many organic substrates (see Sect. 14.4.1).

The action of chelation by siderophores implies multiple acidic functional groups (such as $\mathrm{OH}, \mathrm{COOH}$ ) capable of chelating metals which are involved in successive deprotonation schemes (Edwards et al. 2005; Boukhalfa et al. 2006; Reichard et al. 
(a)

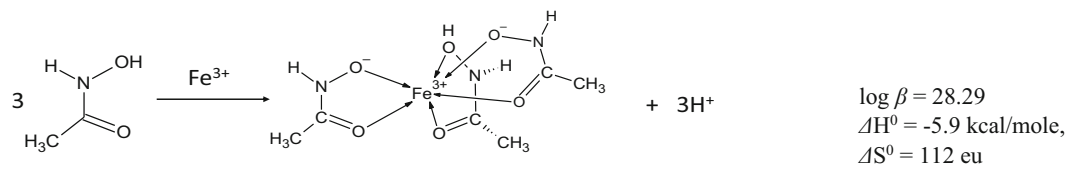

(b)

Hydroxamic acid

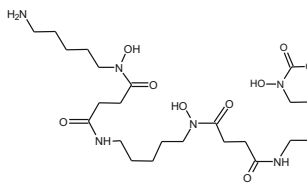

Desferrioxamine B (DFO-B)

trihydroxamate complex

$\Delta \mathrm{H}^{0}=-5.9 \mathrm{kcal} / \mathrm{mole}$,

$\operatorname{og} \beta=30.6$

$\triangle \mathrm{H}^{0}=-19.8 \mathrm{kcal} / \mathrm{mole}$ $\Delta \mathrm{S}^{0}=71$ eu

Fig. 14.1 Chelation schemes: (a) model chelate complex: iron(III) trihydroxamate; (b) ferrioxamine (or desferrioxamine B complex with iron); and (c) ferrioxamine E (or desferrioxamine E complex with iron); modified from Crumbliss (1990)

2007). As acids, they tend to dissociate in their aqueous solutions releasing free hydronium ions $\left(\mathrm{H}_{3} \mathrm{O}^{+}\right)$, thus decreasing the $\mathrm{pH}$ of the solution. Their tendency to dissociate is characterized by their $\mathrm{pKa}$ values; the lower the $\mathrm{pKa}$ value, the stronger the acid. As the deprotonated (mostly anionic) forms are generally capable of metal complexation, their $\mathrm{pK}_{\mathrm{a}}$ values are important as they control the range for their most efficient action.

Siderophores can be categorized according to their functional groups as carboxylates, catecholates, hydroxamates, and mixed type (Neilands 1995; Boukhalfa and Crumbliss 2002; Kraemer 2004; Crichton 2019). A siderophore database can be found on the web (Bertrand 2010); chemical structures of selected siderophores are shown in Fig. 14.2. A brief presentation of the main types of siderophores follows.

\subsubsection{Carboxylate Siderophores}

The carboxylate siderophores contain $\alpha$-hydroxycarboxylic acid moieties, which renders them as acids with a broad range of acidities as seen through their $\mathrm{pKa}$ values. Citric acid has been considered as a model compound (Fig. 14.2a) with pKa values 3.13, 4.76, and 6.40 (Harris 2015) the lowest value assigned to the a-OH carboxyl group (Silva et al. 2009; Heller et al. 2012). The pKa values of carboxyl groups in the siderophore molecules range between 3.5 and 5 (Miethke and Marahiel 2007) and are therefore active for complexation in relatively low $\mathrm{pH}$ values.

These siderophores can coordinate with the metal ion through their electron-rich $\alpha-\mathrm{OH}$ carboxylate oxygens; as a result, they can form chelates at low $\mathrm{pH}$ values, which offer an asset for applications that require an acidic environment. Nature has taken advantage of this fact by utilizing these agents in acidic microbial 

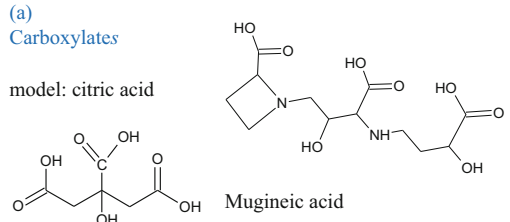

Mugineic acid

(b)

Catecholates

Model: catechol $(1,2$ diphenol)<smiles>Oc1ccccc1O</smiles>

(c)

Hydroxamates

Model: Hydroxamic acid

${ }_{\text {HO }}^{\mathrm{R}} \mathbb{O}_{\mathrm{O}}^{\mathrm{R}}$

(d) Mixed

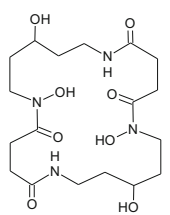

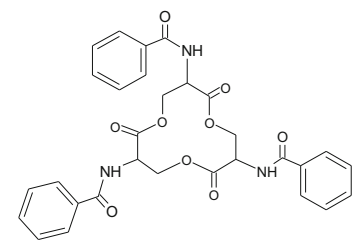

Enterobactin

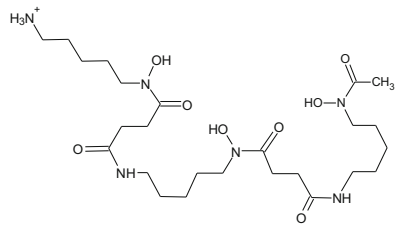

Desferrioxamine B

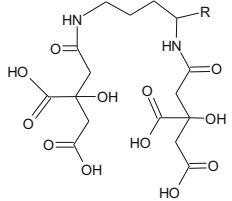

Rhizoferrin $(R=H)$

Staphyloferrin $(\mathrm{R}=\mathrm{COOH})$

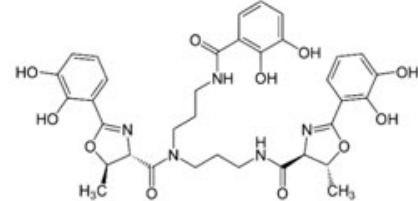

Vibriobactin

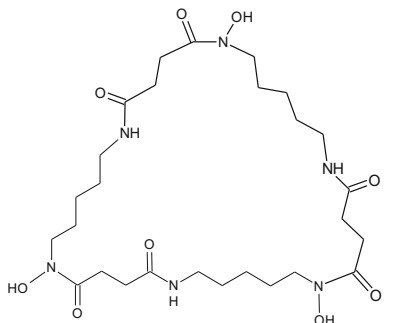

Desferrioxamine E<smiles>CCCCCCC(=O)NCCCCCC(=O)N(O)CCC(=O)NCCCCCN(O)C(=O)CCC(=O)NO</smiles><smiles>CC(=O)N(O)CCCC1NC(=O)C(CCCN(O)C(C)=O)NC1=O</smiles>

Rhodotorulic acid

Pyoverdine (Pseudomonas putida) Catecholate + hydroxamate + citrate

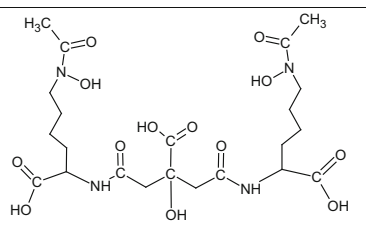

Aerobactin (Aerobacter aerogenes) Hydroxamate + citrate

Fig. 14.2 Chemical structures of typical multidentate chelator classes and corresponding siderophores: (a) carboxylates model: citric acid; (b) catecholates model: catechol (1,2 diphenol); (c) hydroxamates model: hydroxamic acid; and (d) mixed 
environments (Harris et al. 1979). Their $\log \beta$ values are among the lowest in siderophores, typically around 20-30, suggesting that they are among the least stable siderophore complexes; their relatively low chelate stabilities are compensated in nature by achieving concentrations in the rhizosphere as high as $1 \mathrm{mM}$, while the more potent desferrioxamine chelators (see below) can be successful at three orders of magnitude lower concentration (approximately, $1 \mu \mathrm{M}$ ) (Kraemer 2004; Hider and Kong 2010; Ahmed and Holmström 2014). These concentration ranges are also expected to play a similar role in other applications of siderophores in conservation.

\subsubsection{Catecholate Siderophores}

This siderophore type is based on catechols, or 1,2-dihydroxybenzenes (Avdeef et al. 1978; Romero et al. 2018) (Fig. 14.2b), which due to the geometrically favorable acidic phenolic groups can efficiently coordinate to iron. Catechols have been extensively studied due to their antioxidant, as well as pro-oxidant properties (i.e., the indirect oxidative action, by enabling the formation of reactive oxygen species, also suggesting potential antimicrobial action), depending on the conditions (Iwahashi et al. 1989; Moran et al. 1997; Nakamura 2000; Salgado et al. 2013). Especially the pro-oxidant activities occur by increasing the activity of Fenton reagent for reducing $\mathrm{Fe}(\mathrm{III})$ to $\mathrm{Fe}(\mathrm{II})$ and $\mathrm{O}_{2}$ to peroxides $(\bullet \mathrm{OOH})$. These highly energetic and reactive oxygen species play significant roles in wood biodegradation by white and brown rot fungi (Goodell et al. 2006; Romero et al. 2018). These activities are related to their ability for chelation through their catechol phenolate ions, which are formed over $\mathrm{pH}$ 9-10 (Avdeef et al. 1978; Hynes and Ó Coinceanainn 2001). This issue will be further discussed in the following sections.

Catechol-based siderophores show among the highest stability constants for iron chelation; specifically, enterobactin, which is produced by Escherichia coli and other bacteria (Harris et al. 1979; Kraemer 2004) shows the highest known $\log \beta$ value, 39.5 (Table 14.1), meaning that it is the most stable siderophore complex known; in other words, ferric species in contact with this siderophore will prefer the chelation route over any other, leading to the enterobactin-Fe(III) complex. Enterobactin forms hexadentate chelates by coordinating to iron in a "salicylate mode," i.e., using a carbonyl adjacent to a phenolic OH (Correnti and Strong 2012).

\subsubsection{Hydroxamate Siderophores}

Hydroxamate siderophores have drawn a lot of attention as they compose one of the largest and most efficient categories (Ahmed and Holmström 2014). They contain hydroxamic acid moieties (Fig. 14.2c) which bear relatively high acidities (comparable to phenols), thus allowing the formation of hydroxamate ion, which is the actual chelator. Hydroxamic acids have been systematically studied since the 1970s, based on their "unexpectedly" not-so-low acidities (Agrawal 1979; Crumbliss 1990; Yang et al. 2006). Aceto-hydroxamic acid has been used as a model compound for 


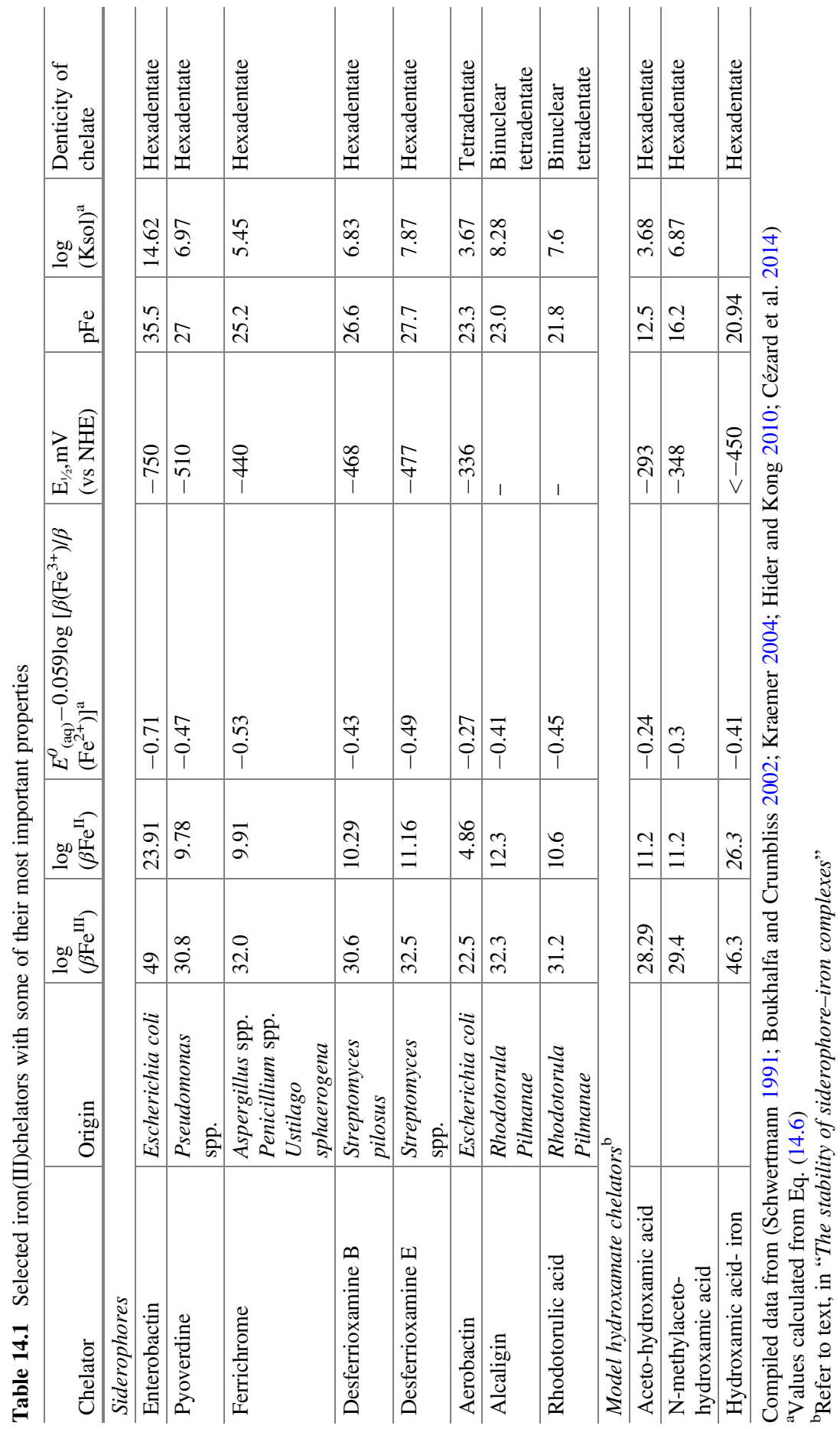


the study of related siderophores; its iron(III) complex shows significant stability with a $\log \beta$ value of 28.3 (Fig. 14.1a) (Boukhalfa and Crumbliss 2002).

The desferrioxamines (often known as deferoxamines) A, B, and $\mathrm{E}$ are among the most well-studied hydroxamate siderophores, carrying three such groups which form 1:1 hexadentate complexes with iron(III), called ferrioxamines (Fig. 14.1b); these show very high $\log \beta$ values 32.0, 30.6, and 32.5, respectively (KonetschnyRapp et al. 1992; Edwards et al. 2005; Sharpe et al. 2011).

Acid dissociation plays here, too, a significant role. The typical $\mathrm{pK}_{\mathrm{a}}$ values of hydroxamate siderophores are generally at 8.5-11 (Singh et al. 2015). In particular, the $\mathrm{pK}_{\mathrm{a}}$ values of desferrioxamine $\mathrm{B}$, one of the most studied, are 8.32, 9.16, 9.94, and 11.44, meaning that their anionic forms (hydroxamate ions) are gradually produced above the corresponding $\mathrm{pH}$ values, and therefore effective complexation may occur in this region.

Denticity is another ruling factor. Rhodotulic acid, alcaligin, and bisucaberin form tetradentate chelates; the former has relatively lower stability ( $\beta$ value 31.2 ), while alcaligin and bisucaberin possess higher stabilities ( $\beta$ values 32.3 and 32.3, respectively) due to their closed ring molecular geometries which are pre-arranged for efficient coordination to iron (Crumbliss 1990; Konetschny-Rapp et al. 1992; Hider and Kong 2010). This closed ring effect is more pronounced for the hexadentate desferrioxamine $\mathrm{E},(\log \beta$ value 32.5$)$. Possibly, the most studied hydroxamate siderophore is desferrioxamine $\mathrm{B}$, an open-ring, hexadentate chelator with $\log \beta$ value of 30.6 , which has also been considered for conservation-related applications (Rapti et al. 2017; Albelda-Berenguer et al. 2019). All above structures are listed in Fig. 14.2.

\subsubsection{Mixed Type Siderophores}

A large number of siderophores carry more than one type of functional group. For instance, aerobactin (see structure in Fig. 14.2d) contains three carboxylate and two hydroxamate groups, which allow complexation with $\log \beta$ of 22.5 (Neilands 1995; Miethke and Marahiel 2007), which is considered as a relatively low stability constant (cf. $\log \beta_{\mathrm{Fe}(\mathrm{III})}$ values in Table 14.1). The participation of the groups in complexation varies significantly over $\mathrm{pH}$, with three protonation steps below 4.5 (carboxylates) and two steps at over 9 (hydroxamates) It is significant to note that complexation starts from $\mathrm{pH}$ value as low as 1 , where half of the total iron is complexed (Harris et al. 1979).

Quite often, mixed type siderophores contain amino acids. For instance, pyoverdine incorporates glycine, serine, aspartic acid, ornithine, and diaminobutyric acid, as well as succinic acid and catechol moieties; in these, $\alpha$-hydroxy-carboxylate, catecholate, and hydroxamate groups are located, all participating in complexation (Boukhalfa and Crumbliss 2002; Boukhalfa et al. 2006; Albelda-Berenguer et al. 2019). Pyoverdine has pKa values 2.72, 3.48, 4.97, 6.40, 8.12, 9.56, 10.24, and 12.88. As a result, complexation may start at low $\mathrm{pH}$ values, while at neutral $\mathrm{pH}$ almost all iron is complexed (Boukhalfa et al. 2006). 


\subsection{The Action: Dissolution of Iron Oxides and Hydroxy-Oxides}

\subsubsection{Acidic Dissolution of Iron Species}

Dissolution of iron oxides and hydroxy-oxides or their transformation into a watersoluble form is necessary for the cleaning of iron-stained objects. The following discussion attempts to present the scientific basis on which the action of siderophores is critical for the dissolution of iron and allowing its availability for nature's nutrition systems as well as for our applications.

In the absence of a chelator, the solubilities of iron oxides, hydroxy-oxides, and hydroxides are characterized by their ion dissociation in water and depend significantly on the $\mathrm{pH}$. The soluble form is the iron(III) aquo complex, $\mathrm{Fe}^{3+}\left(\mathrm{H}_{2} \mathrm{O}\right)_{6}$, sometimes described as $\mathrm{Fe}^{3+}(\mathrm{aq})$. At neutral $\mathrm{pH}$, the ionic solubility of iron oxides, hydroxy-oxides, and hydroxide can be expressed by using goethite $(\alpha-\mathrm{FeOOH})$ as example, according to Eq. (14.2) (Cornell and Schwertmann 2003).

$$
\begin{aligned}
& \text { Neutral environment } \alpha-\mathrm{FeOOH}_{(\mathrm{s})}+\mathrm{H}_{2} \mathrm{O} \rightleftharpoons \mathrm{Fe}^{3+}{ }_{(\mathrm{aq})}+3 \mathrm{OH}^{-} K_{s p} \\
& \quad=\left[\mathrm{Fe}^{3+}\right]\left[\mathrm{OH}^{-}\right]^{3}
\end{aligned}
$$

From Eq. (14.2), the solubility of iron (expressed as $\left[\mathrm{Fe}^{3+}\right]$ ) can be calculated; for this, selected values can be found in Table 14.2, which can be as low as $10^{-13} \mathrm{~mol} / \mathrm{L}$ (Crumbliss 1990; Cornell and Schwertmann 2003; Kraemer 2004). The lowest the $\left[\mathrm{Fe}^{3+}\right]$ concentration, the least soluble and bioavailable is the oxide or hydroxyoxide. The low solubilities of iron oxides and hydroxy-oxides at neutral pH consequently demand strong dissolution strategies in applications aiming at iron uptake. Specifically, goethite and hematite are the least soluble compounds and despite their

\begin{tabular}{|c|c|c|c|c|}
\hline Name & $\begin{array}{l}\text { Chemical } \\
\text { structure }\end{array}$ & $\begin{array}{l}\text { Iron oxidation } \\
\text { state }\end{array}$ & Crystal structure & $\begin{array}{l}\text { Solubility, }[\mathrm{Fe}] \text { at } \\
\mathrm{pH} 7^{\mathrm{a}}\end{array}$ \\
\hline Hematite & $\alpha-\mathrm{Fe}_{2} \mathrm{O}_{3}$ & III & $\begin{array}{l}\text { Rhombohedral } \\
\text { hexagonal }\end{array}$ & $10^{-8.8}-10^{-5.8}$ \\
\hline Maghemite & $\gamma-\mathrm{Fe}_{2} \mathrm{O}_{3}$ & III & Cubic/tetragonal & $10^{-5.0}$ \\
\hline Wüstite & $\mathrm{FeO}$ & II & Cubic & - \\
\hline Magnetite & $\mathrm{Fe}_{3} \mathrm{O}_{4}$ & Mixed II+III & Cubic & - \\
\hline Bernalite & $\mathrm{Fe}(\mathrm{OH}) 3$ & III & Orthorhombic & - \\
\hline Ferrihydrite & $\begin{array}{l}\mathrm{Fe}_{5} \mathrm{O}_{7}(\mathrm{OH})_{4} . \\
\mathrm{H}_{2} \mathrm{O}\end{array}$ & III & Hexagonal & $10^{-3.1}$ \\
\hline Goethite & $\alpha-\mathrm{FeOOH}$ & III & Orthorhombic & $10^{-10.9}-10^{-5.9}$ \\
\hline Akaganeite & $\beta$-FeOOH & III & Monoclinic & - \\
\hline Lepidocrocite & $\gamma$-FeOOH & III & Orthorhombic & $10^{-5.2}$ \\
\hline Ferroxyhyte & $\delta$-FeOOH & III & Hexagonal & - \\
\hline
\end{tabular}

Table 14.2 Selected properties of some iron compounds considered targets for siderophores

${ }^{\mathrm{a}}$ Values from Schwertmann (1991) 
high abundance in the environment, their bioavailability is extremely low because of their low solubilities; as a consequence, their mobilization (or bioavailability through dissolution) becomes a real problem. Also, the same compounds, either as corrosion products or as unwanted iron stain factors, are among the most common iron species, and drastic tools for their removal through dissolution, such as citrate and cystine have been proposed (Kolar et al. 2006; Henniges et al. 2008; Sharpe et al. 2011; Liu et al. 2017).

At acidic $\mathrm{pH}$, the solubility for goethite can be expressed according to Eq. (14.3). The acidic dissolution constant $\left(K^{H}\right)$ values are relatively high as compared to neutral dissolution ones (expressed by $K_{s p}$ values); this means that in order to effectively solubilize such iron species and formation of the water-soluble $\mathrm{Fe}^{3+}$ ion, the $\mathrm{pH}$ needs to be significantly lowered $(\mathrm{pH}<5)$. However, this can be quite prohibitive for substrates in many cultural heritage objects for which $\mathrm{pH}$ values of 6-8 are generally acceptable; on the other hand, this may be a workable region in the case of materials, such as East Asian lacquer, which are stable in acidic $\mathrm{pH}$. The aquo complex of iron $\left[\mathrm{Fe}\left(\mathrm{HO}_{2}\right)_{6}{ }^{3+}\right]$ is also very acidic (Siddall and Vosburgh 1951; Milburn and Vosburgh 1955; Sapieszko et al. 1977; Wilkins 1991; Cotton et al. 1995), and therefore, its presence may lower the solution $\mathrm{pH}$. Moreover, iron(III) can initiate Fenton reactions with detrimental effects on organic substrates (see below).

To complete the picture, the kinetics of dissolution (studying how fast the phenomenon occurs) is equally important as the thermodynamics (studying how stable the chemical species are). Kinetics is directly linked to the mechanism of iron dissolution, which has been studied and has been shown that it is heavily proton dependent. This happens because, as $\mathrm{H}^{+}$ions are adsorbed on the mineral surface, the surface $\mathrm{Fe}^{3+}-\mathrm{OH}$ bonds weaken and the detachment of iron ions is facilitated (Stumm and Furrer 1987; Cornell and Schwertmann 2003). In particular, the initial dissolution of iron(III) is very fast and is subsequently followed by a slower step (Samson and Eggleston 1998; Reichard et al. 2007). This affects the way siderophore molecules work which is able to capture a "burst" of liberated $\mathrm{Fe}^{3+}$ ions during this first step. This proton-mediated process has been found to control all types of dissolution, including the action of siderophores (see below).

\subsubsection{Dissolution of Iron Species in the Presence of Siderophores}

The stability of siderophore-iron complexes: In the presence of a siderophore, the complexation of iron occurs, which is expressed in Eq. (14.4); this involves an acidic environment as protons $\left(\mathrm{H}^{+}\right)$are produced during complexation; however, summing these two equations lead to the combined dissolution reaction, shown in Eq. (14.5) (Kraemer 2004). 


$$
\begin{aligned}
& \text { Acidic environment } \alpha-\mathrm{FeOOH}_{(\mathrm{s})}+3 \mathrm{H}^{+} \rightleftharpoons \mathrm{Fe}^{3+}{ }_{(\mathrm{aq})}+2 \mathrm{H}_{2} \mathrm{O} \\
& \qquad K^{H}{ }_{s}=\frac{\left[\mathrm{Fe}^{3+}\right]}{\left[\mathrm{H}^{+}\right]^{3}}
\end{aligned}
$$

Chelation by siderophore $\mathrm{Fe}^{3+}{ }_{(\mathrm{aq})}+\mathrm{H}_{3} \mathrm{Sid} \rightleftharpoons \mathrm{Fe}-\mathrm{Sid}_{(\mathrm{aq})}+3 \mathrm{H}^{+}$

$$
K_{\text {Sid }}=\frac{[\mathrm{Fe}-\mathrm{Sid}]\left[\mathrm{H}^{+}\right]^{3}}{\left[\mathrm{H}_{3} \mathrm{Sid}\right]\left[\mathrm{Fe}^{3+}\right]}
$$

Sum of (2) and (3) $\alpha-\mathrm{FeOOH}_{(\mathrm{s})}+\mathrm{H}_{3} \mathrm{Sid} \rightleftharpoons \mathrm{Fe}^{3+}{ }_{(\text {aq })}+2 \mathrm{H}_{2} \mathrm{O}$

$$
K_{\mathrm{s}, \mathrm{Sid}}^{H}=\frac{[\mathrm{Fe}-\mathrm{Sid}]}{\left[\mathrm{H}_{3} \mathrm{Sid}\right]}
$$

where Sid is siderophore, $K^{H}{ }_{s}$ the acidic dissolution constant, $K_{\text {Sid }}$ the complex stability constant (often symbolized as $\log \beta$ ), and $K^{H}{ }_{\text {s,Sid }}$ the combined dissolution constant. It appears that the overall process in Eq. (14.5) for siderophores, such as desferrioxamine $\mathrm{B}$ is thermodynamically stable over a wide range of $\mathrm{pH}$ (Kraemer 2004; Kraemer et al. 2005); this has obvious consequences for the usage of such siderophores in their applications.

Focusing on the hydroxamate siderophores, smaller hydroxamic acids, often called "model molecules," are typically used in chemical methodology to better understand the action of more complex, but similar molecules. In this context, chelate complexation by model hydroxamic acids, as compared to that of desferrioxamine B siderophores, can be shown in Fig. 14.1.

For complexation to occur successfully, all energy (or enthalpy) of molecules and ions involved in the destruction of goethite Eq. (14.2) and the formation of the siderophore complex Eq. (14.3) need to decrease. On the other hand, the very strict arrangement of the complex formed in Eq. (14.3) involves increase of molecular ordering (or decrease in entropy); keeping in mind that entropy reflects the disordering of all molecules and ions involved, its decrease imposes a geometric difficulty to complexation. In other words, the decrease in enthalpy is favorable for the reaction, while the decrease in entropy is disfavoring; however, it appears that the contribution of enthalpy is much bigger, and therefore, the complexation occurs successfully.

However, the contribution of entropy is not negligible, and this can explain the more favorable action of cyclic or corona-type siderophores, such as DFO-E, which is more stable (higher $\log \beta$ value) than the non-cyclic DFO-B (Crumbliss 1990). Figure 14.1 shows the chelation reactions of a model hydroxamic acid (Fig. 14.1a) in comparison to DFO-B (Fig. 14.1b) and DFO-E (Fig. 14.1c); in the latter case, the entropy factor is comparatively more favorable. Of the three, desferrioxamine $\mathrm{E}$ (a corona-type, or cyclical molecule) is "pre-arranged" for a favorable chelation; therefore, the final complex has similar cyclic geometry to the precursor and therefore, entropy only slightly decreases. The stability constants of chelation are mathematically linked to both enthalpy and entropy (Crichton 2019), the combined 
consideration of enthalpy and entropy finally explains why DFO-E $(\log \beta=32.5)$ is better complexing agent toward iron(III) than DFO-B $(\log \beta=30.6)$, by almost two orders of magnitude, or 100 times.

The role of $\mathrm{pH}$ : As has already been mentioned above, carboxylate siderophores (Sect. 14.3.2.1) can form complexes in relatively low $\mathrm{pH}$ values, while hydroxamates (Sect. 14.3.2.3) at generally are higher than 8-9. Finally, mixed siderophores, such as pyoverdine (Sect. 14.3.2.4) may form their anionic forms at a much larger span, ranging from 2.7 to 12.9 , meaning that complexes can be produced in significantly lower $\mathrm{pH}$. Therefore, optimal complexation is clearly depending on the acidities in each case. As a result, the simultaneous consideration of the $\log \beta$ values and the deprotonation constants may not allow a straightforward evaluation of the chelation effectiveness of siderophores towards iron(III).

As a more practical approach, the concentration of dissolved iron (expressed as $\mathrm{pFe}$ ) has been proposed to reflect more objectively the effectiveness of complexation (Harris et al. 1979; Albelda-Berenguer et al. 2019). The pFe, defined as $\log \left[\mathrm{Fe}_{\text {free }}\right]$, has been introduced for iron (and accordingly, pM for metals in general), at certain $\mathrm{pH}$, metal and ligand concentrations. High $\mathrm{pFe}$ values mean low free iron concentration and therefore effective complexation. For instance, the high $\log \beta$ value of desferrioxamine B (30.6) corresponds to reasonably high pFe value (26.6); on the other hand, aerobactin, although with significantly lower $\log \beta(22.5)$, has relatively high pFe (23.3) suggesting that it can still adequately complex iron(III). On the other hand, aceto-hydroxamic acid with $\log \beta=28.3$ has low $\mathrm{pFe}$ (12.5). Values of $\mathrm{pFe}$ for various siderophores are shown in Table 14.1.

Selectivity of siderophores towards iron (III): The selectivity of complexation regarding metal ions is an obvious demand for several fields, including that of conservation. Cultural heritage objects often contain metal ions as pigments, corrosion products, depositions, etc., where the selective removal of iron(III) calls for drastic chelating strategies; these generally involve considerable differences for stability constants of chelators towards ferric compounds as compared to other metal ions. In other words, selective cleaning action is needed where the conservator aims to remove a specific metal ion/stain/corrosion product without affecting others.

The drive for choosing iron(III) chelators better than EDTA and DTPA emanates from the fact that these two widely used reagents complex effectively a wide range of metals, such as aluminum, cobalt, nickel, copper, and manganese, which all are present in cultural heritage objects. On the other hand, siderophores show a comparative preference towards iron, which makes these chelators a suitable choice for selective complexation of iron(III) towards other metals. Ferric ion $\left(\mathrm{Fe}^{3+}\right)$ is a hard Lewis acid (see Sect. 14.3.2 for a brief introduction of the hard-soft acid base concept) and therefore shows a high affinity for hard Lewis bases such as most siderophores (Pearson 1973; Crumbliss 1990; Jensen 1991).

In addition, it has been shown that siderophores are particularly sensitive to the electronegativity $\left(\chi_{M}\right)$ of metal ions as well as their charge $(Z)$; the value of $\chi_{M} \bullet Z$ for $\mathrm{Fe}^{3+}$ is 5.9, while for $\mathrm{Al}^{3+}$ and $\mathrm{Cu}^{2+}$ is 4.9 and 4.0, respectively. As a result of the above, the stability constants of DFO-B towards iron(III) is by far higher than any other metal ion $(\log \beta=30.7)$, followed by aluminum $(\log \beta=23.1), \mathrm{Cu}^{2}$ 
Table 14.3 Comparison of overall stability constants $(\beta)$ between representative chelators towards common metal ions

\begin{tabular}{l|l|l|l}
\hline \multirow{2}{*}{ Metal } & \multicolumn{3}{|l}{ Stability constants $(\beta)$} \\
\cline { 2 - 4 } & $\mathrm{DFO}^{\mathrm{a}}$ & $\mathrm{EDTA}^{\mathrm{b}}$ & $\mathrm{DTPA}^{\mathrm{c}}$ \\
\hline $\mathrm{Fe}^{3+}$ & 30.7 & 25.1 & 27.5 \\
\hline $\mathrm{Fe}^{2+}$ & 7.2 & 14.3 & 16.0 \\
\hline $\mathrm{Ca}^{2+}$ & $9.0^{\mathrm{d}}$ & 10.6 & 10.9 \\
\hline $\mathrm{Ni}^{2+}$ & 10.9 & 18.4 & 20.2 \\
\hline $\mathrm{Cu}^{2+}$ & 14.1 & 18.8 & 21.1 \\
\hline $\mathrm{Zn}^{2+}$ & 10.1 & 16.5 & 18.4 \\
\hline $\mathrm{Cd}^{2+}$ & 7.9 & 16.5 & 19.9 \\
\hline $\mathrm{Al}^{3+}$ & 23.1 & 16.4 & - \\
\hline
\end{tabular}

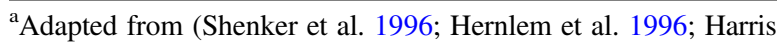
2015)

${ }^{\mathrm{b}}$ Harris (2015)

${ }^{\mathrm{c}}$ Values from Rivers and Ummey (2003)

${ }^{\mathrm{d}}$ Value from Keberle (2006)

${ }^{+}(\log \beta=14.1), \mathrm{Zn}^{2+}(\log \beta=10.1)$ (Shenker et al. 1996; Hernlem et al. 1996). For comparison reasons, values of stability constants for other chelators towards common metal ions are given in Table 14.3. These values can be used to predict the effectiveness of cleaning solutions to selectively chelate metals.

\subsubsection{Effects of Siderophores on the Reduction of Iron(III)}

A significant issue underlying why we mostly care about the presence of iron(III) in cultural heritage artifacts is the fact that it is readily reduced generally to iron (II) through complex chemical cycles involving deleterious reactive intermediates; because of this, iron(III) is often termed as "active iron" (Bulska and Wagner 2005), responsible for significant damage in cellulosic materials (see Sect. 14.4.1). Therefore, from the conservator's point, stabilizing iron(III) may prevent deleterious cycles as the Fenton reaction on this type of substrates.

Iron(III) species may readily be reduced to iron(II); these two forms represent a couple involving the oxidizing agent and the corresponding reducing agent, respectively; these are termed the redox couple iron(III) /iron(II). As a measure of the tendency for the iron(III) $\rightarrow$ iron(II) reaction, the reduction potential $\left(E_{0}\right)$ measured in Volts $\left(25^{\circ} \mathrm{C}, 1.0 \mathrm{M}\right.$ aqueous solution) is a critical factor. In aqueous solution, the reduction potential of $\mathrm{Fe}^{3+} \rightarrow \mathrm{Fe}^{2+}$ is $E_{0}=+0.77 \mathrm{~V}$, which means that this reduction is a spontaneous process in solution (Cotton et al. 1995, Cornell and Schwertmann 2003, Crichton 2019). Generally, the higher the $E_{0}$ value, the higher the tendency for reduction of iron(III) to iron(II). On the other hand, lower $E_{0}$ values mean lower tendency for reduction; even more, when these values are negative, the tendency is minimal and the iron(III) form is stabilized (Cotton et al. 1995; Pepper and Gentry 2015).

Controlling iron(III) reduction through siderophore chelation: In the light of the above, the tendency for reduction of iron(III) may change for other forms such as 
iron oxides and chelate complexes. In particular, siderophore chelates of iron(III) show negative reduction potentials, meaning that iron(III) is practically not reduced to iron(II); for instance, values for DFO-B and enterobactin are -478 and $-750 \mathrm{mV}$, respectively, meaning that enterobactin is a superior stabilizing agent and that reduction of iron(III) is no longer spontaneous, unless a very strong reducing agent is available (Dhungana and Crumbliss 2005).

Microorganisms and plants after complexing non-bioavailable iron(III) in its oxides and hydroxy-oxides, they need to utilize it as nutrient, often by reducing it to a more available form (see Sect. 14.3.3.4). For this, exceptionally strong reducing agents are needed, with negative reduction potentials (for instance, NADH, or hydrogen-nicotinamide dinucleotide, with $E_{0}=-320 \mathrm{mV}$ ) to override the complex stability and finally rendering it in the more bioavailable iron(II). This strategy succeeds in many cases, but fails for the more stable complexes, such as the enterobactin-iron(III) complex (Boukhalfa and Crumbliss 2002). This is a desired situation for applications such as conservation, because mild reducing agents (such as polyphenols) are typically present in cellulosic materials, which consequently are not strong enough to reduce iron from its siderophore complexes.

Very negative $E_{0}$ values, such as those mentioned, do not allow unwanted redox reactions, such as the Haber-Weiss cycle and more particular the Fenton reaction (see Sect. 14.4.1) which produces hydroxyl radical $(\bullet \mathrm{OH})$ and the superoxide ion $\left(\bullet \mathrm{O}^{2-}\right)$, which are highly reactive oxygen species, harmful to organic substrates (Hider and Kong 2010). For the benefit of conservation practice, a conservator needs to be aware of processes such as the Fenton reaction, which is responsible for most of damage in cellulosic materials; because of these, strategies for the decrease for unwanted redox reactions are direly needed (Dhungana and Crumbliss 2005; Albelda-Berenguer et al. 2019). The importance of this process in conservation will be discussed in the following section.

Careful choice of complexing agents towards iron involves the selection of chelators with suitable $\beta$ values for their iron(III) and (II) chelates. It has been proposed that the higher the ratio of the $\beta$ value of siderophore complex of iron (III) $\left(\beta^{\mathrm{Fe}(\mathrm{III})-\mathrm{Sid}}\right)$ with respect to that of iron(II) $\left(\beta^{\mathrm{Fe}(\mathrm{II})-\mathrm{Sid}}\right)$, the better the suppression of the unwanted redox cycles (Boukhalfa et al. 2006; Albelda-Berenguer et al. 2019).

$$
E_{\mathrm{Fe}(\mathrm{III})-\mathrm{Sid}}=E_{a q}^{0}-59 \log \frac{\beta^{\mathrm{Fe}(\mathrm{III})-\mathrm{Sid}}}{\beta^{\mathrm{Fe}(\mathrm{II})-\mathrm{Sid}}}
$$

Selected $\log \beta$ values towards iron(III) and iron(II) are shown in Table 14.3. Other strong iron chelators, such as EDTA notoriously fail to prevent Fenton reactions, as the $\beta$ values between the two iron species are not very different. This is a strong motif towards a better practice concerning the removal of iron from organic substrates. 


\subsubsection{The Kinetics and Mechanisms of Siderophore Action}

The thermodynamic stability of complexes (often called thermodynamic stability) and the rates of reactions such as dissolution and complexation have been already encountered in Sect. 14.3.3.1 The thermodynamics of siderophore-mediated iron(III) and the corresponding chemical equilibria of complexation do not offer a complete picture of the process and the conditions that favor it unless the kinetics are equally considered (Römheld 1991). As already mentioned in Sect. 14.3.3.1, understanding goethite removal from substrates is critical to comprehend the necessity for potent chelators. This has been recognized in conservation, as it has been recognized in living systems.

The rates of goethite dissolution in the absence of chelator are depending on acidity. It has been shown that the detachment of iron from its mineral surface is triggered by an $\mathrm{H}^{+}$-depending mechanism (Samson et al. 2000). It appears that $\mathrm{pH}$ plays a significant role in dissolution rates, which are related to the mechanisms of iron removal from its crystal lattice sites on goethite and other minerals (Monzyk and Crumbliss 1979; Brink and Crumbliss 1984).

A mechanism has been proposed, generally involving three steps. It has been found that during the first step, which is the faster, siderophore molecules of the solution are consumed, thus decreasing their local concentration around iron spots; this may negatively influence the overall effectiveness of complexation in an application, unless high concentrations of siderophores are employed (Hider and Kong 2010). In the subsequent steps, gradual complexation occurs, involving bidentate and hexadentate complexes of iron(II) in a progressive mode (Furrer and Stumm 1986; Kraemer 2004; Reichard et al. 2007).

Specifically in the first step, the complexation process involves competition between the chelator and protons provided by the solution towards iron(III). A similar competition has been observed when a second chelator (or a co-chelator) is added. This is an interesting outcome at the application level: as the rates of complexation by siderophores are favored by acidity, as well as, synergistically to other agents as co-chelators, such as oxalic acid (Brink and Crumbliss 1984; Crumbliss 1990; Cheah et al. 2003; Kraemer 2004).

Regarding applications in cultural heritage, the above mechanistic considerations, in combination with what has been presented in the context of thermodynamic stability of siderophore-iron complexes may impose extra difficulties regarding the effect of acidity, and they consequently demand for careful design of siderophore-based strategies.

Dechelation of captured iron(III): The stability of siderophore complexes does not allow for their easy destruction (often called dechelation). The iron-uptake process by microorganisms and plant roots from their immediate geo-environment eventually involves a later stage for releasing chelated iron. This involves specific mechanisms, as the exceptionally high stabilities of the chelate complexes do not allow for easy complex dissociation, often called dechelation (Boukhalfa and Crumbliss 2002; Dhungana and Crumbliss 2005). 
Although this is a desired property regarding conservation-related applications, living systems need (and finally succeed) to achieve dechelation, because complexed iron, although soluble, is still non-bioavailable. The reduction strategy by bacteria involving potent reducing agents (such as NADH) has been presented above; in conservation, although reducing agents in substrates such as wood are generally milder, this needs to be taken into account for targeted cleaning strategies.

This is achieved by proton-assisted mechanisms and/or by reducing iron(III) to iron(II), where the corresponding complex of the latter is less stable by many orders of magnitude (Table 14.3). The proton-assisted dechelation mechanism has been studied extensively and showed that dechelation rates significantly increase at lower $\mathrm{pH}$ values. Although the siderophore complexes are extremely stable, in low $\mathrm{pH}$ can be labile, this factor has been found to favorably affect dechelation pathways for the benefit of living systems. In the case of iron stain cleaning, $\mathrm{pH}$ needs to be seriously considered regarding the balance between iron capture by chelation and release by dechelation (Boukhalfa and Crumbliss 2002).

\subsubsection{Side Reactions, Synergistic Effects, and Light Sensitivity}

The Fenton-type reactions that were mentioned in the Sect. 14.1 are of significant concern for the various applications as they act detrimentally to most substrates. While chelators such as EDTA do not prevent Fenton reactivity of iron(III) (AlbeldaBerenguer et al. 2019), it has been reported that siderophores, such as desferrioxamine $\mathrm{B}$ and enterobactin do not favor this type of unwanted sidereactions.

A synergistic effect between dicarboxylic acids and siderophores has been observed; increase of iron(III) dissolution rates through complexation by desferrioxamine B in the presence of oxalate was observed (Reichard et al. 2007; Loring et al. 2008; Albelda-Berenguer et al. 2019). The similar accelerating effect was observed with other dicarboxylic acids, such as fumaric, malonic, and succinic; on the other hand, citric acid was found to inhibit the rates, possibly due to adsorption competition effects (Reichard et al. 2007).

Light also seems to play a significant role in the final dechelation stages and the bioavailability of iron in marine systems. In particular, some iron(III) complexes with marine siderophores have been found to dechelate the metal through a photolysis mechanism which leads to the final release of ferrous ions (Hider and Kong 2010). Studies using aquachelin (a mixed type siderophore contains hydroxamate and $\alpha$-hydroxy-carboxylate groups) have been shown to react photochemically towards releasing an iron(III) photoproduct complex, which undergoes a ligand-tometal charge-transfer process, resulting in the reduction of iron(III) to iron (II) (Barbeau et al. 2001, 2003). The latter is easily released and therefore, available to the benefit of iron-starving organisms. On the reasonable basis that photolytic processes may affect the effectiveness of applications employing iron(III) chelation by siderophores, this issue merits further investigation for other siderophore types as well. 


\section{Application of Siderophores in Conservation}

\subsection{The Detrimental Effect of Iron}

Museum artifacts such as furniture, toys, musical instruments, tools, household utensils, manuscripts, and religious items are often consisted of organic materials, such as wood, textile, paper, leather, and elements made of iron. When these composite objects are become wet or are exposed to humid environments, their iron elements corrode, and the formed corrosion products may accumulate on the surface of the organic substrate or they may impregnate its matrix.

The most common iron corrosion products formed are iron(III) (ferric) and iron (II) (ferrous) oxides, such as $\mathrm{Fe}_{2} \mathrm{O}_{3}, \mathrm{Fe}_{3} \mathrm{O}_{4}$, and $\mathrm{FeO}$, hydroxy-oxides such as $\mathrm{FeOOH}$, occurring in various polymorphs, often also called oxy-hydroxides and iron hydroxide $\mathrm{Fe}(\mathrm{OH})_{3}$. Iron corrosion products generally exhibit very low solubilities, which depend on their grain size, since the smaller the size the higher the solubility. Therefore, for some compounds such as hematite and goethite, solubility increases, as their grain size can be extremely small ranging between 10 and $150 \mathrm{~nm}$. In addition, other hydroxy-oxides of iron(III), such as ferrihydrite $\left(\mathrm{Fe}_{5} \mathrm{O}_{7}(\mathrm{OH}) .4 \mathrm{H}_{2} \mathrm{O}\right)$, may also exist as corrosion products and are considered significant participants in the overall iron corrosion process (Kraemer 2004). Hematite (red), magnetite (black), and goethite (pale brown-yellow, beige) have also been historically used as pigments. In Table 14.2, a list of the most abundant forms of iron compounds found on cultural heritage objects is presented (Cornell and Schwertmann 2003; Scott and Eggert 2009; Richards et al. 2012).

The destructive effect of iron on organic substrates, which can be either cellulosic or proteinaceous, has been the subject of several studies. Metal ions, when found in proximity to organic substrates, take part in redox reactions and act as catalysts to oxidation processes of these substrates. These processes are a wide variety of chemical reactions leading to the formation of various deterioration products and to depolymerization of main chemical components of organic substrates and consequently to the reduction of their mechanical strength (Baker 1980; Timár-Balázsy and Eastop 1998; Strlič et al. 2001; Scott and Eggert 2009; Badillo-Sanchez et al. 2019).

The oxidation of organic materials is probably caused by the free hydroxyl radical formation and hydrogen peroxide, which allow the Fenton-type reactions to occur. Thus, during the oxidation of ferrous iron to its ferric state, the free radical formation might be enhanced if organic substrates are present and this in turn leads to the formation of organic radicals, as seen in Eqs. (14.7a)-(14.7d), or to the formation of hydrogen peroxide, as seen in Eqs. (14.7e)-(14.7f) (Neevel 1995). The hydrogen peroxide produced during oxidation of organic substrates is decomposed by reacting further with ferrous ions and forms additional hydroxyl radicals, according to Eqs. (14.7e) and (14.7f). 


$$
\begin{gathered}
\mathrm{Fe}^{2+}+\mathrm{O}_{2} \rightarrow \mathrm{Fe}^{3+}+\mathrm{O}-\mathrm{O} \bullet- \\
\mathrm{Fe}^{3+}+\mathrm{O}-\mathrm{O} \bullet-+\mathrm{RH} \rightarrow \mathrm{R} \bullet+\mathrm{HOO} \bullet+\mathrm{Fe}^{2+} \\
\mathrm{R} \bullet+\mathrm{O}_{2} \rightarrow \mathrm{ROO} \bullet \\
\mathrm{ROO} \bullet+\mathrm{RH} \rightarrow \mathrm{ROOH}+\mathrm{R} \bullet \\
\mathrm{Fe}^{2+}+\mathrm{HOO} \bullet+\mathrm{H}^{+} \rightarrow \mathrm{Fe}^{3+}+\mathrm{H}_{2} \mathrm{O}_{2} \\
\mathrm{Fe}^{2+}+\mathrm{H}_{2} \mathrm{O}_{2} \rightarrow \mathrm{Fe}^{3+}+\mathrm{HO} \bullet+\mathrm{OH}^{-}
\end{gathered}
$$

The latter equation is often referred to as "Fenton reaction" (Gupta et al. 2016), although there is still considerable controversy among chemists in the reaction mechanism and the products obtained from that reaction. Some researchers claim that the Fenton mechanism involves hydroxyl radicals $(\mathrm{OH} \bullet)$ formation, whereas others report the generation of other oxidizing iron species, such as ferryl ion $\left(\mathrm{FeO}^{2}\right.$ ${ }^{+}$) (Wardman and Candeias 1996; Strlič et al. 2001; Barbusiński 2009). Nevertheless, the mixture of hydrogen peroxide and the ferrous ion is called the Fenton reagent and it is a strong oxidant of organic materials, such as wood, textile, and paper. Its oxidative properties depend on the hydrogen peroxide concentration, the ratio of ferrous ion to hydrogen peroxide, the $\mathrm{pH}$, and the reaction time (Barbusiński 2009). The severe oxidation mechanism of organic substrates has been intensely studied and the catastrophic role of hydroperoxides and the hydroxyl free radicals $(\mathrm{OH} \bullet)$ has been also demonstrated (Emery and Schroeder 1974; Zeronian and Inglesby 1995; Kolar 1997).

Based on the above it becomes clear that the removal of iron corrosion products from museum artifact combining organic substrates, such as wood, textile, paper is an urgent issue during the conservation processes.

\subsection{The Problem of Conventional Chelators' Use in Conservation}

There are many published studies on the removal of iron corrosion products from substrates, such as paper, textile, stone, metal, paintings, waterlogged wood by using chelating agents such as citric acid, di-ammonium and tri-ammonium citrate, EDTA (ethylene-diaminetetraacetic acid), DTPA (diethylene-triaminepenta-acetic, or pentetic acid) (Hart 1981; Hofenk de Graaff 1982; Banik and Ponahlo 1983; Slavin 1990; Burgess 1991; Häkäri 1992; Phenix and Burnstock 1992; Chapman 1997; Margariti 2003; Rivers and Ummey 2003; Almkvist et al. 2005; Fors 2008). However, those substances are not always giving consistent results concerning their efficacy in removing iron corrosion products and as mentioned previously they lack specificity for iron and promote unwanted side reactions due to their tendency for the production of hydroxyl radicals. Furthermore, there are several 
studies giving considerable attention to the environmental impact and the biodegradability of conventional chelators, such as EDTA and DTPA, which are extensively used, in the conservation field, especially on waterlogged objects (Sillanpää 1997; Nörtemann 1999; Grčman et al. 2001; Nörtemann 2005; Kołodyńska 2011). EDTA, however, has been found to be more persistent than DTPA in degradation by conventional biological and physicochemical methods (Nörtemann 1999; Grčman et al. 2001; Nörtemann 2005). Although DTPA is more biodegradable, it has been reported that EDTA can be one of its decomposition products (Sillanpää 1997). Nonetheless, both EDTA and DTPA may result in several risks when released to the aquatic environment, as they may contribute to toxicity at significantly low concentrations (Sillanpää 1997; Grčman et al. 2001). Additionally, their degradation products can be used as a nitrogen source for algae growth and thus EDTA and DTPA have the potential to contribute to eutrophication (Sillanpää 1997; Kołodyńska 2011).

\subsection{Applications of Siderophores in Conservation of Cultural Heritage Objects}

The tendency nowadays is to find safer alternative materials and methods for conservation purposes. This tendency though, becomes a necessity, considering the established national legislations and international environmental restrictions (Balliana et al. 2016) and therefore the replacement of conventional chelators with new ones with improved biodegradability, is critical.

There are a few studies regarding the removal of iron corrosion products from cultural heritage objects, with "green" compounds such as siderophores (Wagner and Bulska 2003; Rapti et al. 2015, 2017; Albelda-Berenguer et al. 2019). These studies have investigated the application of siderophores, mainly desferrioxamine $\mathrm{B}$ (DFO-B), on different organic substrates and preservation states. The application methodologies followed by both siderophores and conventional chelators were not similar and therefore comparative analysis of the obtained results cannot be done.

\subsubsection{Extraction of Iron from Historical Manuscripts With Iron Gall Ink}

Bulska and Wagner (2005) dealt with historic manuscripts written with iron gall inks ${ }^{1}$ that contained a substantial amount of "active" iron(II) ions, which can act as

\footnotetext{
${ }^{1}$ Historical recipes for gall ink production involve the use of aqueous solutions of iron(II) sulfate with extracts of gall nuts to form complexes of oxidized iron(III) with gallic acid. However, most of historical manuscripts contain an excess of iron(II) ions that were not complexed and thus are active iron(II) ions that can act as catalysts to oxidative degradation processes of paper.
} 
catalysts and are responsible for promoting the degradation processes of paper cellulose via Fenton reactions. In order to prevent this paper degradation process, which is often accompanied by acid hydrolysis among other deteriorative mechanisms, Bulska and Wagner (2005) tried to find a cleaning treatment to remove the excess of active iron ions. The treatment was expected, without altering the iron gall ink color, to impede both Fenton reaction and acid hydrolysis leaving the paper of the manuscripts unaffected by the cleaning procedure. Therefore, they comparatively evaluated conventional chelators versus siderophores for their efficiency of iron extraction on mock-ups mimicking historical manuscripts with iron gall inks and on mock-ups simulating only the amount of active iron ions. Chelators were required to demonstrate low cleaning efficacy on the first mock-up type and concurrently high on the second type of mock-ups. Moreover, they attempted to simultaneously neutralize the acidity of papers (deacidification) during the cleaning treatment.

Several physicochemical analyses were implemented in order to design the cleaning methodology and to evaluate the efficacy of the cleaning treatments, including Scanning Electron Microscopy (SEM), X-ray Fluorescence Spectrometry (XRF), Graphite Furnace Atomic Absorption Spectrometry (GFAAS), Inductively Coupled Plasma Spectrometry (ICM-MS), Molecular spectroscopy (UV/VIS), X-ray Absorption Near-Edge Structure (XANES) (Bulska et al. 2001; Wagner et al. 2001a, 2001b; Wagner and Bulska 2003; Bulska and Wagner 2004; Wagner and Bulska 2004).

The chelators used for iron extraction and iron complex formation included bidentate ligand acetylacetone, dibenzoylmethane, diethylene-triaminepenta-acetic acid (DTPA), the potassium-magnesium salt of phytic acid and the mesylate salt of DFO-B. All compounds were selected due to their inhibition effect of further formation of hydroxyl radicals and to their high stability constants of complexes with iron as it was expected to be more effective and phytate, a known compound for its beneficial iron deactivation effect, as it reduces iron ability to undergo further reactions and occupy all coordination sites of iron (Neevel 1995). The solutions of the examined chelators were prepared at various concentrations $(0.001,0.005$, and $0.01 \mathrm{M})$ and $\mathrm{pH}$ values in the range of $7-9$, in addition to that obtained after the chelators' dissolution in water (low $\mathrm{pH}<3$ ). Ethanol/water solutions $(10,25$, and $50 \%$ ) of DTPA, phytic acid, and DFO-B were also examined at $0.005 \mathrm{M}$. The mockups were immersed in the various chelators' solutions for 20 min (Bulska et al. 2001; Wagner et al. 2001b; Wagner and Bulska 2003).

Results obtained by physicochemical analyses showed that iron-DFO-B complex formation at both types of mock-ups was above $80 \%$. Moreover, on mock-ups mimicking the excess of active iron ions, DFO-B revealed an increase of iron extraction, which depended mainly on the $\mathrm{pH}$ of solution. The concentration of all prepared solutions of chelators was pronouncedly higher than the amount of iron ions need to be extracted. In particular, at $\mathrm{pH} 8$, a value typically used in paper conservation to enhance deacidification, and solution concentration of $0.005 \mathrm{M}$, iron extraction reached ca. 91\%. Among all the tested $\mathrm{pH}$, the lowest extraction of $67-72 \%$ was observed at the highest concentration $0.01 \mathrm{M}$. Concerning applications on mock-ups simulating manuscripts with iron gall ink, DFO-B with a concentration 
of $0.005 \mathrm{M}$ also showed high extraction capacity which reached 83 and $85 \%$, at $\mathrm{pH} 8$ and 9, respectively (Wagner and Bulska 2003). However, this was considered a drawback because iron extraction was not selective, as the color of iron gall ink was severely affected. Consequently, the most effective solution for removing excess iron was proved unsuitable for iron gall ink mock-ups.

The influence of $\mathrm{pH}$ on siderophores' efficacy has been also the subject of several environmental studies unrelated to conservation. Borer et al. (2009) among others (Cheah et al. 2003; Borer et al. 2005; Reichard et al. 2005; Loring et al. 2008) investigated DFO-B and aerobactin in order to improve the understanding of these siderophores biogeochemistry and to gain information about siderophores reactivity towards the dissolution and mobilization of iron hydroxy-oxides, such as goethite and lepidocrocite, which are often found in terrestrial and aquatic environments. Their study revealed that $\mathrm{pH}$ influences the iron adsorption in ferric compounds, for instance, in lepidocrocite via DFO-B and that was also associated with siderophores' functional group and their deprotonation stage. More specifically, they showed that the maximum absorption of lepidocrocite by DFO-B occurred at $\mathrm{pH} 8.6$, which is close to its first $\mathrm{pKa}$ (8.3), whereas at lower or higher $\mathrm{pH}$ values, the adsorption was decreased.

\subsubsection{Extraction of Iron Compounds from Composite Museum Objects}

Rapti et al. (2015) investigated in a preliminary study the removal of iron ions from dry wooden substrates, which cannot tolerate waterborne treatments, due to the hygroscopic and anisotropic nature of wood. Desferrioxamine, in the form of a commercial injectable drug, Desferal ${ }^{\circledR}$ manufactured by Novartis, was compared with the conventional chelators EDTA and DTPA to treat wooden mock-ups artificially stained with iron corrosion products. To avoid immersion in aqueous solutions and minimize the amount of water that would penetrate into the wood and at the same time maintain the cleaning potency of the solution applied, the chelators were applied by cotton swab and carboxymethyl cellulose gel (CMC) $4.5 \% \mathrm{w} / \mathrm{v}$. The effectiveness of the two conventional chelators was also examined with the addition of a reducing agent, sodium dithionite (SDT) (Selwyn and Tse 2009). The solutions of EDTA and DTPA were prepared at $2.5 \% \mathrm{w} / \mathrm{v}$ with or without the addition of SDT $(5 \% \mathrm{w} / \mathrm{v})$ at $\mathrm{pH} 6.2$, and 6.8, respectively, whereas DFO-B concentration was $5 \times 10^{-5} \mathrm{M}$, at $\mathrm{pH} 8.5$. Colorimetry and elemental analysis by Energy Dispersive $\mathrm{X}$-ray (EDX) spectroscopy were implemented before and after cleaning for evaluating the efficacy of the chelators. Results showed that DFO-B was an effective chelator, as efficient as EDTA when SDT was added to it. However, residues of Na and S ions were detected, owed to SDT, which have the potential to promote future deterioration of substrates and therefore, this suggest the need to avoid SDT as part of the chelators solutions on this type of substrate; thus, siderophore was considered more appropriate. Conventional chelators when applied without the reducing agent were shown clearly less efficient. 
Further comparative investigation of Desferal ${ }^{\circledR}$, EDTA, and DTPA was undertaken by Rapti et al. (2017). In this study, the cleaning potential of chelators combined with gel formulations when applied on dry composite objects comprising of wood, textiles, and iron was examined. Gel formulations were selected as they could be easily applied, clean the substrate in a more controlled and selective way and at the same time minimize the diffusion of the aqueous solution within the wood without though reducing its cleaning efficiency. Moreover, the use of gels has the advantage of avoiding dismantling the composite object, as cleaning can be achieved selectively at the stained substrate. For that purpose, wood and textile mock-ups were artificially stained with iron corrosion products. Chelator solutions (Desferal ${ }^{\circledR}$, EDTA, and DTPA) were prepared $\left(3 \times 10^{-2} \mathrm{M}\right)$, and accordingly applied with several gel formulations (Klucel G 10\% w/v, agarose A0701 4\% w/v, Carbopol $9402.5 \mathrm{w} / \mathrm{v}$ neutralized by Ethomeen C25 $15 \mathrm{v} / \mathrm{v}$ and xanthan gum $2.2 \mathrm{w} / \mathrm{v}$ ). The $\mathrm{pH}$ of Desferal ${ }^{\circledR}$ was adjusted to 8.45 and 6.8, of EDTA to 6.2 and DTPA 6.8, according to their acid dissociation constants and to the substrate compatibility in order to avoid deterioration processes caused by the cleaning procedure. The time of application was not set, since it varied depending on the color change caused by complexation. The gel was removed after colored complexes were formed (EDTA ferric complex is pale yellow, DTPA complex is yellow, while DFO-B is orangered) (Almkvist et al. 2005; Dominguez-Vera 2004); the process was repeated with fresh identical gels until complexation was no longer observed, followed by a rinse with swab wetted in $50 \% \mathrm{v} / \mathrm{v}$ ethanol aqueous solution. The effectiveness of all chelators was assessed by colorimetry and energy dispersive X-ray (EDX) spectroscopy before and after the cleaning procedure.

The colorimetry measurements $\left(\mathrm{L}^{*}, \mathrm{a}^{*}, \mathrm{~b}^{*}\right)$ showed that the $\mathrm{L}^{*}$ and $\mathrm{b}^{*}$ coordinates increased in all samples after cleaning, indicating that samples became brighter and yellower. In contrast, $\mathrm{a}^{*}$ factor was reduced due to the partial removal of the red-brown iron corrosion products. The total color difference $\left(\Delta \mathrm{E}^{*}\right)$ indicates the cleaning efficacy; the higher the difference the more effective cleaning of mock-ups. Regarding the textile mock-ups, DFO-B at $\mathrm{pH} 6.8$ showed the greatest change when gelled with Klucel G, followed by xanthan gum (Fig. 14.3a). In contrast, DFO-B at $\mathrm{pH} 8.4$ exhibited the second highest $\Delta \mathrm{E}^{*}$ of all the cleaning methods employed, when applied with xanthan gum instead of Klucel G. Moreover, the DTPA application provided similar $\Delta \mathrm{E}^{*}$ to DFO at $\mathrm{pH} 8.4$, whereas EDTA was the least effective, with the exception of the agarose gel. Although the results of $\Delta \mathrm{E}^{*}$ values of both substrates suggested that the gelling agents were actually involved in the effectiveness in cleaning efficacy, it was not possible to draw any conclusions, as the results obtained were not consistent for all chelators. Analogous results on the chelators' efficacy were obtained for wooden mock-ups.

Furthermore, elemental analysis by Energy Dispersive X-ray spectroscopy (EDX) demonstrated the weight percent of the detected iron before and after the cleaning of wood and textile mock-ups (Fig. 14.3b). More specifically, DFO-B at both pHs (6.8 and 8.45) proved superior to EDTA and DTPA in its performance for removing iron corrosion products, and this is consistent with its higher stability constant. In contrast to colorimetry measurements, EDX results were more 


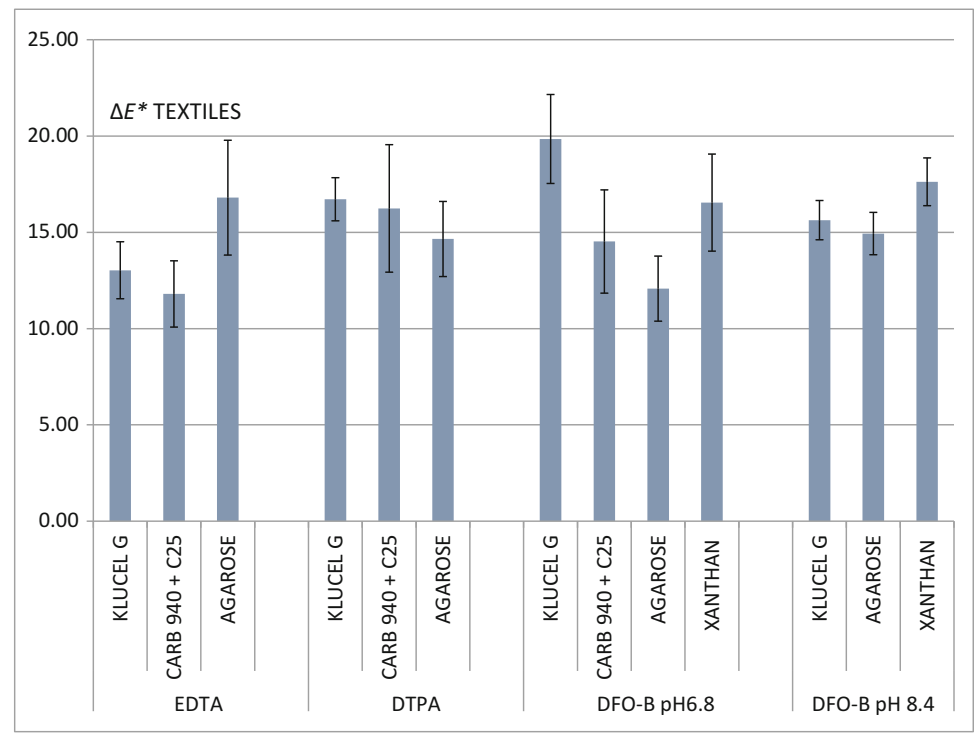

(a)

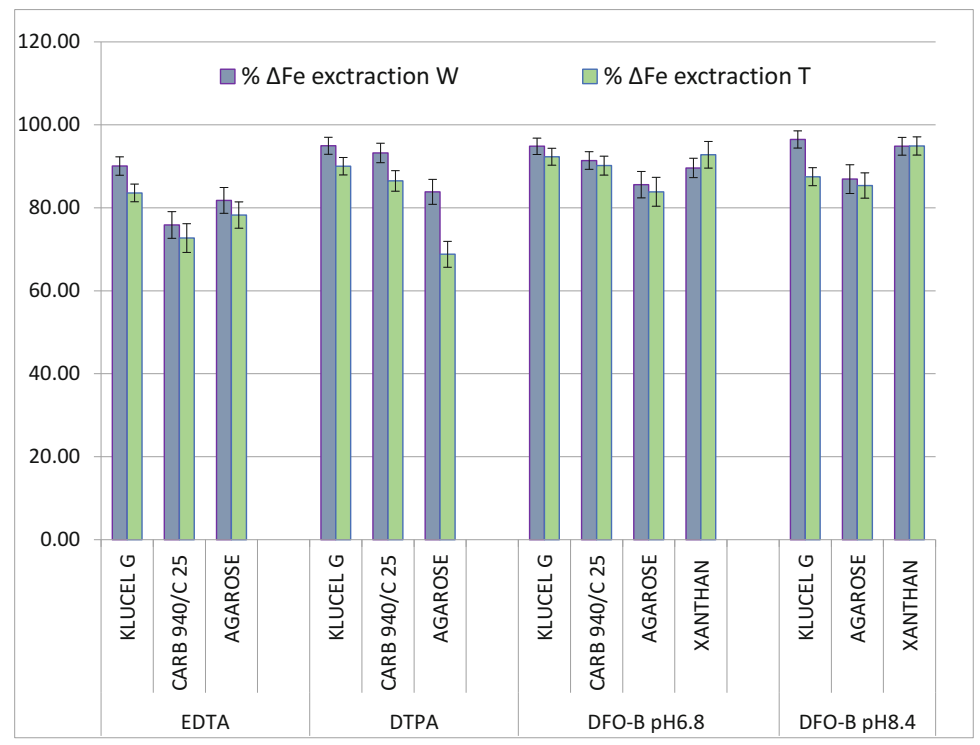

(b)

Fig. 14.3 (a) $\Delta \mathrm{E}^{*}$ colorimetry values obtained after cleaning textile mock-ups with different chelators and gel formulations; (b) EDX results of iron extraction demonstrated by the weight percentages of iron difference $(\Delta \mathrm{Fe})$ before and after the cleaning of wooden and textile mock-ups with different chelators and gel formulations, based on Rapti et al. (2017). $W$ wood; $T$ textile 
consistent and showed that the efficacy of the chelators in iron extraction was influenced by the gelling agents. In the case of DFO-B at both $\mathrm{pH}$ values, EDTA and DTPA, gels prepared with Klucel G seemed to be more effective than other gelling agents.

Finally, as observed by EDX and confirmed by colorimetry results, wood was cleaned more effectively than the textile and this is possibly due to the fact that iron oxides have been impregnated deeper within the textile fibers (Glenn et al. 2015). Although iron corrosion products were not completely removed from either substrate, the overall appearance of both mock-ups was improved.

\subsubsection{Extraction of Iron Oxides and Iron Sulfides From Waterlogged Wood}

Albelda-Berenguer et al. (2019) under the framework of the MICMAC project (microbes for archeological wood conservation) investigated the production and subsequent application of siderophores in extraction and stabilization of sulfur and iron compounds found in waterlogged archeological wood. Pyoverdine (produced from the fluorescent Pseudomonas putida) was employed as the selected siderophore, due to the fact that its chromophore (see Fig. 14.2d) offers an additional asset for its spectrophotometric detection. This was studied along with Desferal ${ }^{\circledR}$ and EDTA on mock-ups made of balsa wood that were artificially impregnated either with iron oxides or iron sulfides through immersion for $24 \mathrm{~h}$ in each chelator solution (20 mM, pH 7). The formation of iron complexes was visually evaluated, based on the fact that each iron-chelator complex acquires a unique color upon formation (Dominguez-Vera 2004; Almkvist et al. 2005). More specifically, pyoverdine changes from yellow-green to red-brown upon iron(III) complexation (Hohnadel and Meyer 1986). Repetition of the process with new solutions is needed to be applied to promote further iron extraction. Colorimetry measurements were conducted on the wooden mock-ups after the cleaning process. Results showed that mock-ups impregnated with iron sulfides were more efficiently cleaned than those prepared with iron oxides, which remained almost unchanged. Pyoverdine was showed to be the most effective for the iron sulfides removal during the cleaning application.

Albelda-Berenguer et al. (2019) ongoing study is focusing on the development of an application protocol employing siderophores for extracting iron oxides or iron sulfides found in waterlogged archeological wood of shipwreck timbers. Moreover, the extraction of iron from known iron minerals by the use of siderophores is also a target of this ongoing work in order to demonstrate their ability in complexing iron. In this regard, iron sulfides present in three mineral phases, mackinawite ( $\mathrm{FeS}$ ), pyrite $\left(\mathrm{FeS}_{2}\right)$, and mineral sulfur $\alpha$-S8 along with iron oxides (hematite) and oxy-hydroxides (goethite) are being tested with pyoverdine, Desferal ${ }^{\circledR}$, and EDTA at different $\mathrm{pH}$. Preliminary results revealed that pyoverdine could extract iron from mackinawite, pyrite, and goethite, but is not capable to extract it from hematite (Monachon et al. 2019). 


\subsubsection{Other Studies with Siderophores}

Besides the above-mentioned studies, other disciplines employing siderophores as possible preventive antioxidants of cellulose deterioration can be considered as indirect approaches to conservation issues (Strlič et al. 2001). The use of siderophores as antioxidants has been investigated in the food industry (Todokoro et al. 2016; Albelda-Berenguer et al. 2019). Strlič et al. (2001) studied whether DFO-B, phytate, EDTA and DTPA chelators were possible preventive antioxidants of cellulose degradation, as it typically constitutes several museum objects. Their antioxidant role was investigated concerning the formation of stable complexes and the occupation of all the available coordination sites of iron. The inhibition of hydroxyl radical production during degradation of cellulose was comparatively investigated in aqueous systems containing the above-mentioned chelators by calculating their rate constants. Their efficiency concerning their antioxidant behavior at $20^{\circ} \mathrm{C}$ (range tested: $20-80^{\circ} \mathrm{C}$ ) and in the $\mathrm{pH}$ range from 6.5 to 8 was found to be higher for DFO-B followed by phytate and DTPA.

\section{Conclusions}

The research investigations on siderophores were initially conducted mostly due to their significant roles in making iron available for living systems by chelating ferric compounds from terrestrial and aquatic habitats. These roles have provided an impressive body of biological, chemical, and biochemical data which have greatly helped in introducing those agents for several applications in fields such as medicine, agriculture, environmental research, and materials science. However, despite their high potential, these materials have only recently been introduced in fields such as the conservation of cultural heritage. Nonetheless, some promising research results in this field show that the siderophores are highly useful materials due to their chelating abilities which allow for efficient and safe practices in conservation.

Siderophores, as naturally occurring chelators, have been considered as "green" chemical substances with low environmental risk. Their high affinity to iron and the potential for minimum harm to museum objects may rank them among the most promising novel materials with potentially significant uses in the conservation field. However, factors such as their complex stability constants, the working conditions (such as the $\mathrm{pH}$ range, interfering metal ions and light), along with kinetic considerations regarding chelation and dechelation need to be examined and balanced before these compounds are recommended for a specific use. So far, only desferrioxamine B and pyoverdine have been investigated for cleaning cultural heritage objects. Nonetheless their application although limited to few organic substrates seems to provide promising results for the effective removal of iron corrosion products. In order to develop widely accepted strategies employing these powerful agents for conservation treatments further investigation efforts are needed, mainly 
concerning the understanding of their properties and optimizing their application. The following issues are among those that need to be considered:

- The formation of highly stable complexes requires a certain $\mathrm{pH}$ range, depending on the nature of siderophores; therefore, $\mathrm{pH}$ needs to be adjusted to avoid both iron dechelation and the harmful side-reactions to the object. These demands are typically ad hoc defined, based on the specific properties of each cultural heritage substrate, so that the risk for further damage due to a siderophore-based application is minimized.

- Selectivity issues towards interfering metals need also to be investigated. Balancing acidity and redox conditions can potentially increase selectivity. Moreover selectivity of one type of iron compound over others based on their solubilities, redox behavior, etc., need also to be addressed.

- Application on complex or composite materials, in particular, those incorporating inorganic components need some attention as siderophores can be beneficial for one substrate and damaging for another.

- The significant synergistic effect of similarly chelating dicarboxylic acids present can be further exploited for enhanced and optimized action. The parallel functioning of some of these acids (such as malonic and succinic) as $\mathrm{pH}$ buffering agents may also offer an additional asset.

- The incorporation of siderophores in gel systems needs also to be addressed and their specific action towards various substrates needs to be further investigated.

- Sensitivity to UV and visible light is a clearly underestimated issue. In addition, the fluorescence chromophores that are included in the structures of some siderophores may point toward additional applications, as well as for some extra caution.

Taking into account these issues, the optimization and fine-tuning of siderophorebased applications on wood, textile, paper, etc. are possible. The information about siderophores' efficacy, in combination with different application methodologies, should be a starting point for their future broader application in conservation.

\section{References}

Agrawal YK (1979) Hydroxamic acids and their metal complexes. Russ Chem Rev 48:948-963

Ahmed E, Holmström SJM (2014) Siderophores in environmental research: roles and applications. Microb Biotechnol 7:196-208

Albelda-Berenguer M, Monachon M, Joseph E (2019) Siderophores: from natural roles to potential applications, 1st edn. Elsevier, Amsterdam, The Netherlands

Ali SS, Vidhale NN (2013) Bacterial siderophore and their application: a review. Int J Curr Microbiol App Sci 2:303-312

Almkvist G, Dal L, Persson I (2005) Extraction of iron compounds from VASA wood. In: Hoffmann P, Spriggs JA, Strætkvern K, Gregory D (eds) Proceedings of the 9th ICOM-CC group on wet organic archaeological materials conference, Copenhagen, 7-11 June, 2004, ICOM, Bremerhaven, pp 202-210 
Avdeef A, Sofen SR, Bregante TL, Raymond KN (1978) Coordination chemistry of microbial iron transport compounds. 9: stability constants for catechol models of enterobactin. J Am Chem Soc 100:5362-5370

Badillo-Sanchez D, Chelazzi D, Giorgi R, Cincinelli A, Baglioni P (2019) Understanding the structural degradation of south American historical silk: a Focal Plane Array (FPA) FTIR and multivariate analysis. Sci Rep 9:1-10

Baker AJ (1980) Corrosion of metal in wood products. In: Sereda PJ, Litvan GG (eds) Durability of building materials and components, American Society for Testing and Materials (ASTM) STP 691, pp 981-993

Balliana E, Ricci G, Pesce C, Zendri E (2016) Assessing the value of green conservation for cultural heritage: positive and critical aspects of already available methodologies. Int J Conserv Sci 7 (1):185-202

Banik G, Ponahlo J (1983) Some aspects of degradation phenomena of paper caused by green copper-containing pigments. The Paper Conservator 7(1):3-7

Barbeau K, Rue EL, Bruland KW, Butler A (2001) Photochemical cycling of iron in the surface ocean mediated by microbial iron(III)-binding ligands. Nature 413:409-413

Barbeau K, Rue EL, Trick CG, Bruland KW, Butler A (2003) Photochemical reactivity of siderophores produced by marine heterotrophic bacteria and cyanobacteria based on characteristic Fe(III) binding groups. Limnol Oceanogr 48:1069-1078

Barbusiński K (2009) Fenton reaction-controversy concerning the chemistry. Ecol Chem Eng 16 (3):347-358

Barton LL, Hemming BC (eds) (1993) Iron chelation in plants and soil microorganisms. Academic Press, New York

Bauer L, Exner O (1974) The chemistry of hydroxamic acids and n-hydroxyimides. Angew Chem Int Ed Engl 13:376-384

Bertrand S (2010) Siderophore base. The web data base of microbial siderophores. http:// bertrandsamuel.free.fr/siderophore_base/siderophores.php. Accessed 2 Jan 2020

Bertrand S, Larcher G, Landreau A, Richomme P, Duval O, Bouchara J-P (2009) Hydroxamate siderophores of Scedosporium apiospermum. BioMetals 22:1019-1029

Borer P, Hug SJ, Sulzberger B, Kraemer SM, Kretzschmar R (2009) ATR-FTIR spectroscopic study of the adsorption of desferrioxamine $\mathrm{B}$ and aerobactin to the surface of lepidocrocite $(\gamma$-FeOOH). Geochim Cosmochim Acta 73(16):4661-4672

Borer PM, Sulzberger B, Reichard P, Kraemer SM (2005) Effect of siderophores on the lightinduced dissolution of colloidal iron(III) (hydr)oxides. Mar Chem 93(2-4):179-193

Boukhalfa H, Crumbliss AL (2002) Chemical aspects of siderophore mediated iron transport. BioMetals 15:325-339

Boukhalfa H, Reilly SD, Michalczyk R, Iyer S, Neu MP (2006) Iron(III) coordination properties of a pyoverdin siderophore produced by Pseudomonas putida ATCC 33015. Inorg Chem 45:5607-5616

Brink CP, Crumbliss AL (1984) Kinetics, mechanism, and thermodynamics of aqueous iron(III) chelation and dissociation: influence of carbon and nitrogen substituents in hydroxamic acid ligands. Inorg Chem 23:4708-4718

Bulska E, Wagner B (2002) Investigation of iron-gall ink corrosion of ancient manuscript by non-destructive and microanalytical methods. In: van Grieken R, Janssens K, Van't dack L, Meersman G (eds) Art 2002: 7th international conference on non-destructive testing and microanalysis for the diagnostics and conservation of the cultural and environmental heritage, 2-6 June 2002, Congress Centre Elzenveld, Antwerp, Belgium: Proceedings, University of Antwerp

Bulska E, Wagner B (2004) A study of ancient manuscripts exposed to iron-gall ink corrosion. In: Janssens K, Van Grieken R (eds) Comprehensive analytical chemistry. Elsevier, Amsterdam, pp 755-788

Bulska E, Wagner B (2005) Investigation of a novel conservation procedure for historical documents. In: Van Grieken R, Janssens K (eds) Cultural heritage conservation and environmental 
impact assessment by non-destructive testing and micro-analysis. A.A Balkema Publishers, London, pp 101-116

Bulska E, Wagner B, Sawicki MG (2001) Investigation of complexation and solid-liquid extraction of iron from paper by UV/VIS and atomic absorption spectrometry. Microchim Acta 136 (1-2):61-66

Burgess H (1991) The use of chelating agents in conservation treatments. The Paper Conservator 15 (1):36-44

Burkitt MJ (2003) Chemical, biological and medical controversies surrounding the Fenton reaction. Prog React Kinet Mech 28:75-104

Cézard C, Farvacques N, Sonnet P (2014) Chemistry and biology of pyoverdines, pseudomonas primary siderophores. Curr Med Chem 22:165-186

Chapman V (1997) The conservation of a painted silk tambourine-and tri-ammonium citrate. In: Lockhead V (ed) Painted textiles, UKIC textile section forum postprints, 21 April 1997, UKIC, London

Cheah S-F, Kraemer SM, Cervini-Silva J, Sposito G (2003) Steady-state dissolution kinetics of goethite in the presence of desferrioxamine B and oxalate ligands: implications for the microbial acquisition of iron. Chem Geol 198:63-75

Cornell RM, Schwertmann U (2003) The iron oxides: structure, properties, reactions. In: Occurrences and uses, 2nd edn. VCH Verlag, Weinheim, Germany

Corregidor V, Viegas R, Ferreira LM, Alves LC (2019) Study of iron gall inks, ingredients and paper composition using non-destructive techniques. Heritage 2:2691-2703

Correnti C, Strong RK (2012) Mammalian siderophores, siderophore-binding lipocalins, and the labile iron pool. J Biol Chem 287:13524-13531

Cotton FA, Wilkinson G, Gaus PL (1995) Basic inorganic chemistry. John Wiley \& Sons, New York

Crichton R (2019) Biological inorganic chemistry, 3rd edn. Academic Press, London

Crumbliss A (1990) Iron bioavailability and the coordination chemistry of hydroxamic acids. Coord Chem Rev 105:155-179

Devireddy LR, Hart DO, Goetz DH, Green MR (2010) A mammalian siderophore synthesized by an enzyme with a bacterial homolog involved in enterobactin production. Cell 141:1006-1017

Dhungana S, Crumbliss AL (2005) Coordination chemistry and redox processes in siderophoremediated iron transport. Geomicrobiol J 22:87-98

Dominguez-Vera JM (2004) Iron(III) complexation of Desferrioxamine B encapsulated in apoferritin. J Inorg Biochem 98(3):469-472

Dunford H (2002) Oxidations of iron(II)/(III) by hydrogen peroxide: from aquo to enzyme. Coord Chem Rev 233-234:311-318

Edwards DC, Nielsen SB, Jarzecki AA, Spiro TG, Myneni SCB (2005) Experimental and theoretical vibrational spectroscopy studies of acetohydroxamic acid and desferrioxamine B in aqueous solution: effects of $\mathrm{pH}$ and iron complexation. Geochim Cosmochim Acta 69:3237-3248

Emery JA, Schroeder HA (1974) Iron-catalyzed oxidation of wood carbohydrates. Wood Sci Technol 8(2):123-137

Fors Y (2008) Sulfur-related conservation concerns for marine archaeological wood: the origin, speciation and distribution of accumulated sulfur with some remedies for the VASA. PhD Thesis, Department of Physical, Inorganic and Structural Chemistry, Stockholm University

Furrer G, Stumm W (1986) The coordination chemistry of weathering: I. dissolution kinetics of ס-Al 2 O 3 and BeO. Geochim Cosmochim Acta 50:1847-1860

Glenn S, Haldane E-A, Hackett J and Sung I (2015) Borrowing from the neighbours: using the technology of other disciplines to treat difficult textile conservation problems. In: Fairhurst A (ed) Learning curve: education, experience and reflexion icon textile spring forum postprints, 13 April 2015, Icon, London

Goodell B, Daniel G, Jellison J, Qian Y (2006) Iron-reducing capacity of low-molecular-weight compounds produced in wood by fungi. Holzforschung 60:630-636 
Grčman H, Velikonja-Bolta Š, Vodnik D, Kos B, Leštan D (2001) EDTA enhanced heavy metal phytoextraction: metal accumulation, leaching and toxicity. Plant Soil 235(1):105-114

Gupta P, Lakes A, Dziubla T (2016) A free radical primer. In: Dziubla T, Butterfield DA (eds) Oxidative stress and biomaterials. Academic Press, Cambridge, pp 1-33

Häkäri AE (1992) The removal of rust stains from historic cellulosic textile material. Unpublished Diploma Dissertation, Textile Conservation Centre, London

Harris DC (2015) Quantitative chemical analysis. 8th edn

Harris WR, Carrano CJ, Raymond KN (1979) Coordination chemistry of microbial iron transport compounds. 16: isolation, characterization, and formation constants of ferric aerobactin. J Am Chem Soc 101:2722-2727

Hart JR (1981) Chelating agents in the pulp and paper industry. Tappi 64(3):43-44

Heller A, Barkleit A, Foerstendorf H, Tsushima S, Heim K, Bernhard G (2012) Curium(III) citrate speciation in biological systems: a europium(III) assisted spectroscopic and quantum chemical study. Dalton Trans 41:13969

Henniges U, Reibke R, Banik G, Huhsmann E, Hähner U, Prohaska T, Potthast A (2008) Iron gall ink-induced corrosion of cellulose: aging, degradation and stabilization. Part 2: application on historic sample material. Cellulose 15:861-870

Hernlem BJ, Vane LM, Sayles GD (1996) Stability constants for complexes of the siderophore desferrioxamine B with selected heavy metal cations. Inorg Chim Acta 244:179-184

Hider RC, Kong X (2010) Chemistry and biology of siderophores. Nat Prod Rep 27:637

Hofenk de Graaff JH (1982) Some recent developments in the cleaning of ancient textiles. In: Bromelle NS, Thomson G (eds) Science and technology in the service of conservation. IIC, London, pp 93-95

Höfte M (1993) Classes of microbial siderophores. In: BL L, HB C (eds) Iron chelation in plants and soil microorganisms. Academic Press, New York, pp 3-27

Hohnadel D, Meyer JM (1986) Pyoverdine-facilitated iron uptake among fluorescent Pseudomonads. In: Swinburne TR (ed) Iron, siderophores, and plant diseases. NATO ASI series (series a: life sciences), vol 117. Springer, Boston, pp 119-129

Hynes MJ, Ó Coinceanainn M (2001) The kinetics and mechanisms of the reaction of iron(III) with gallic acid, gallic acid methyl ester and catechin. J Inorg Biochem 85:131-142

Ito Y, Butler A (2005) Structure of synechobactins, new siderophores of the marine cyanobacterium Synechococcus sp. PCC 7002. Limnol Oceanogr 50:1918-1923

Iwahashi H, Morishita H, Ishii T, Sugata R, Kido R (1989) Enhancement by catechols of hydroxylradical formation in the presence of ferric ions and hydrogen peroxide. J Biochem 105:429-434

Jablonský M, Kazíková J, Holúbková S (2010) The effect of the iron-gall ink on permanence in paper by breaking length, degree of polymerisation and thermogravimetric stability of paper during accelerated ageing. Acta Chim Slov 3:63-73

Jensen WB (1991) Overview lecture: the Lewis acid-base concepts: recent results and prospects for the future. J Adhes Sci Technol 5:1-21

Kalinowski DS, Richardson DR (2005) The evolution of iron chelators for the treatment of iron overload disease and cancer. Pharmacol Rev 57:547-583

Keberle H (2006) The biochemistry of desferrioxamine and its relation to iron metabolism. Ann N Y Acad Sci 119:758-768

Khan A, Singh P, Srivastava A (2018) Synthesis, nature and utility of universal iron chelatorsiderophore: a review. Microbiol Res 212-213:103-111

Kolar J (1997) Mechanism of autoxidative degradation of cellulose. Restaurator 18:163-176

Kolar J, Štolfa A, Strlič M, Pompe M, Pihlar B, Budnar M, Simčič J, Reissland B (2006) Historical iron gall ink containing documents-properties affecting their condition. Anal Chim Acta 555:167-174

Kolar J, Strlic M (2001) Stabilisation of ink corrosion. In: Jean E, Brown A (eds) The Iron gall ink meeting. University of Northumbria, Newcastle-upon-Tyne, UK, pp 135-139

Kolar J, Strlič M (2004) Ageing and stabilisation of paper. National and University Library, Turjaška 1, 1000 Ljubljana, Slovenia, Ljubljana 
Kołodyńska D (2011) Chelating agents of a new generation as an alternative to conventional chelators for heavy metal ions removal from different waste waters. In: Ning RY (ed) Expanding issues in desalination. InTech, Rijeka, pp 339-370

Konetschny-Rapp S, Jung G, Raymond KN, Meiwes J, Zähner H (1992) Solution thermodynamics of the ferric complexes of new desferrioxamine siderophores obtained by directed fermentation. J Am Chem Soc 114:2224-2230

Koppenol WH (1993) The centennial of the Fenton reaction. Free Radic Biol Med 15:645-651

Kraemer SM (2004) Iron oxide dissolution and solubility in the presence of siderophores. Aquat Sci-Res Across Boundaries 66:3-18

Kraemer SM, Butler A, Borer P, Cervini-Silva J (2005) Siderophores and the dissolution of ironbearing minerals in marine systems. In: Banfield JF, Cervini-Silva J, Nealson K (eds) Molecular geomicrobiology. De Gruyter, Berlin, Boston, pp 53-84

Kumar L, Meena NL, Singh U (2016) Role of phytosiderophores in acquisition of iron and other micronutrients in food legumes. In: Singh U, Praharaj C, Singh S, Singh N (eds) Biofortification of food crops. Springer, New Delh, pp 291-302

Liu Y, Kralj-cigić I, Strlič M (2017) Kinetics of accelerated degradation of historic iron gall ink-containing paper. Polym Degrad Stab. https://doi.org/10.1016/j.polymdegradstab.2017.07.010

Loring JS, Simanova AA, Persson P (2008) Highly mobile iron pool from a dissolutionreadsorption process. Langmuir 24:7054-7057

Margariti C (2003) The use of chelating agents in textile conservation: an investigation of the efficiency and effects on the use of three chelating agents for the removal of copper and iron staining from cotton textiles. In: Dawson L, Berkouwer M (eds) Dust, sweat and tears: recent advances in cleaning techniques, UKIC Textile Section, AGM Spring Forum, 7 April 2003, UKIC, London, pp 28-38

Marusak RA, Doan K, Cummings SD (2006) Integrated approach to coordination chemistry: an inorganic laboratory guide, John Wiley \& Sons, New Jersey

Miethke M, Marahiel MA (2007) Siderophore-based iron acquisition and pathogen control. Microbiol Mol Biol Rev 71:413-451

Milburn RM, Vosburgh WC (1955) A spectrophotometric study of the hydrolysis of iron(III) ion. II: polynuclear species. J Am Chem Soc 77:1352-1355

Monachon M, Albelda-Berenguer M, Joseph E (2019) Bio-based treatment for the extraction of problematic iron sulphides from waterlogged archaeological wood. In: Book of abstracts of the 14th ICOM-CC group on wet organic archaeological materials conference, Portsmouth, UK, 20-24 May 2019, ICOM, Portsmouth, pp 46-47

Monzyk B, Crumbliss AL (1979) Mechanism of ligand substitution on high-spin iron(III) by hydroxamic acid chelators: thermodynamic and kinetic studies on the formation and dissociation of a series of monohydroxamatoiron(III) complexes. J Am Chem Soc 101:6203-6213

Moran JF, Klucas RV, Grayer RJ, Abian J, Becana M (1997) Complexes of iron with phenolic compounds from soybean nodules and other legume tissues: prooxidant and antioxidant properties. Free Radic Biol Med 22:861-870

Nakamoto K (2009) Infrared and Raman spectra of inorganic and coordination compounds. In: Theory and applications to inorganic chemistry, 6th edn. John Wiley \& Sons, New York

Nakamura Y (2000) A simple phenolic antioxidant protocatechuic acid enhances tumor promotion and oxidative stress in female ICR mouse skin: dose- and timing-dependent enhancement and involvement of bioactivation by tyrosinase. Carcinogenesis 21:1899-1907

Neevel JG (1995) Phytate: a potential conservation agent for the treatment of ink corrosion caused by iron gall inks. Restaurator 16(3):143-160

Neilands JB (1995) Siderophores: structure and function of microbial iron transport compounds. J Biol Chem 270:26723-26726

Nörtemann B (1999) Biodegradation of EDTA. Appl Microbiol Biotechnol 51(6):751-759

Nörtemann B (2005) Biodegradation of chelating agents: EDTA, DTPA, PDTA, NTA, and EDDS. Biogeochemistry of chelating agents. ACS symposium series, American Society, Washington, DC, pp 150-170 
Pearson R (1973) Hard and soft acids and bases. Dowden, Hutchinson and Ross, Stroudsburg

Pepper IL, Gentry TJ (2015) Earth environments. In: Pepper IL, Gerba CP, Gentry TJ (eds) Environmental microbiology. Elsevier, Amsterdam, pp 59-88

Phenix A, Burnstock A (1992) The removal of surface dirt on paintings with chelating agents. The Conservator 16(1):28-38

Rapti S, Boyatzis S, Rivers S, Velios A, Pournou A (2017) Removing iron stains from wood and textile objects: assessing gelled siderophores as novel green chelators. In: Angelova LV, Ormsby B, Townsend JH, Wolbers R (eds) Gels in the conservation of art. Archetype Books, London, pp 343-348

Rapti S, Rivers S, Pournou A (2015) Removing iron corrosion products from museum artefacts: Investigating the effectiveness of innovative green chelators. In: International conference Science in Technology, SCinTE, Athens

Reichard PU, Kraemer SM, Frazier SW, Kretzschmar R (2005) Goethite dissolution in the presence of phytosiderophores: rates, mechanisms, and the synergistic effect of oxalate. Plant Soil 276 (1-2):115-132

Reichard PU, Kretzschmar R, Kraemer SM (2007) Dissolution mechanisms of goethite in the presence of siderophores and organic acids. Geochim Cosmochim Acta 71:5635-5650

Renshaw JC, Robson GD, Trinci APJ, Wiebe MG, Livens FR, Collison D, Taylor RJ (2002) Fungal siderophores: structures, functions and applications. Mycol Res 106:1123-1142

Richards V, Kasi K, Godfrey I (2012) Iron removal from waterlogged wood and the effects on wood chemistry. In: Straetkvern K, Williams E, (eds) Proceedings of the 11th ICOM-CC group on wet organic archaeological materials conference, ICOM, Greenville, 2010. Lulu, Greenville, pp 383-400

Rivers S, Ummey N (2003) Conservation of furniture. Butterworth-Heinemann, Oxford

Romero R, Salgado PR, Soto C, Contreras D, Melin V (2018) An experimental validated computational-method for pKa determination of substituted 1,2-dihydroxybenzenes. Front Chem 6:1-11

Römheld V (1991) The role of phytosiderophores in acquisition of iron and other micronutrients in graminaceous species: an ecological approach. Plant Soil 130:127-134

Saha M, Sarkar S, Sarkar B, Sharma BK, Bhattacharjee S, Tribedi P (2016) Microbial siderophores and their potential applications: a review. Environ Sci Pollut Res 23:3984-3999

Saha R, Saha N, Donofrio RS, Bestervelt LL (2013) Microbial siderophores: a mini review. J Basic Microbiol 53:303-317

Salgado P, Melin V, Contreras D, Moreno Y, Mansilla HD (2013) Fenton reaction driven by iron ligands. J Chil Chem Soc 58:2096-2101

Samson SD, Eggleston CM (1998) Active sites and the non-steady-state dissolution of hematite. Environ Sci Technol 32:2871-2875

Samson SD, Stillings LL, Eggleston CM (2000) The depletion and regeneration of dissolutionactive sites at the mineral-water interface: I. Fe, Al, and in sesquioxides. Geochim Cosmochim Acta 64:3471-3484

Sapieszko RS, Patel RC, Matijevic E (1977) Ferric hydrous oxide sols. 2: thermodynamics of aqueous hydroxo and sulfato ferric complexes. J Phys Chem 81:1061-1068

Schwertmann U (1991) Solubility and dissolution of iron oxides. In: Plant and soil; selected papers from the fifth international symposium on iron nutrition and interactions in plants, pp 1-25

Scott DA, Eggert G (2009) Iron and steel in art: corrosion, colorants, conservation. Archetype Publications, London

Selwyn L, Tse S (2009) The chemistry of sodium dithionite and its use in conservation. Stud Conserv 54:61-73

Sharpe PC, Richardson DR, Kalinowski DS, Bernhardt PV (2011) Synthetic and natural products as iron chelators. Curr Top Med Chem 11:591-607

Shenker M, Chen Y, Hadar Y (1996) Stability constants of the fungal siderophore rhizoferrin with various microelements and calcium. Soil Sci Soc Am J 60:1140 
Siddall TH, Vosburgh WC (1951) A spectrophotometric study of the hydrolysis of iron(III) ion. J Am Chem Soc 73:4270-4272

Sillanpää M (1997) Environmental fate of EDTA and DTPA. Reviews of environmental contamination and toxicology, vol 152. Springer, New York, pp 85-111

Silva AMN, Kong X, Hider RC (2009) Determination of the pKa value of the hydroxyl group in the $\alpha$-hydroxycarboxylates citrate, malate and lactate by 13C NMR: implications for metal coordination in biological systems. BioMetals 22:771-778

Singh N, Karpichev Y, Sharma R, Gupta B, Sahu AK, Satnami ML, Ghosh KK (2015) From $\alpha$-nucleophiles to functionalized aggregates: exploring the reactivity of hydroxamate ion towards esterolytic reactions in micelles. Org Biomol Chem 13:1-8

Slavin J (1990) The removal of salt deposits from decorative paintings on paper. In: Hackney S, Townsend JH, Eastaugh N (eds) Dirt and pictures separated, UKIC and tate gallery conference, UKIC, London, pp 49-50

Strlič M, Kolar J, Pihlar B (2001) Some preventive cellulose antioxidants studied by an aromatic hydroxylation assay. Polym Degrad Stab 73(3):535-539

Stumm W, Furrer G (1987) The dissolution of oxides and aluminum silicates: examples of surfacecoordination-controlled-kinetics. In: Stumm W (ed) Aquatic surface chemistry. John Wiley and Sons, Somerset, NJ, pp 97-219

Sugiura Y, Nomoto K (1984) Phytosiderophores structures and properties of mugineic acids and their metal complexes. In: Siderophores from microorganisms and plants: structure and bonding, vol 58. Springer, Heidelberg; Berlin, pp 107-135

Thiem D, Złoch M, Gadzała-Kopciuch R, Szymańska S, Baum C, Hrynkiewicz K (2018) Cadmium-induced changes in the production of siderophores by a plant growth promoting strain of Pseudomonas fulva. J Basic Microbiol 58:623-632

Timár-Balázsy AT, Eastop D (1998) Chemical principles in textile conservation. ButterworthsHeinemann, London

Todokoro T, Fukuda K, Matsumura K, Irie M, Hata Y (2016) Production of the natural iron chelator deferriferrichrysin from Aspergillus oryzae and evaluation as a novel food-grade antioxidant. J Sci Food Agric 96(9):2998-3006

Tseng CF, Burger A, Mislin GLA, Schalk IJ, Yu SSF, Chan SI, Abdallah MA (2006) Bacterial siderophores: the solution stoichiometry and coordination of the Fe(III) complexes of pyochelin and related compounds. J Biol Inorg Chem 11:419-432

Wagner B, Bulska E (2003) Towards a new conservation method for ancient manuscripts by inactivation of iron via complexation and extraction. Anal Bioanal Chem 375:1148-1153

Wagner B, Bulska E (2004) On the use of laser ablation inductively coupled plasma mass spectrometry for the investigation of the written heritage. J Anal At Spectrom 19 (10):1325-1329

Wagner B, Bulska E, Hulanicki A, Heck M, Ortner HM (2001a) Topochemical investigation of ancient manuscripts. Fresenius J Anal Chem 369(7-8):674-679

Wagner B, Bulska E, Meisel T, Wegscheider W (2001b) Use of atomic spectrometry for the investigation of ancient manuscripts. J Anal At Spectrom 16(4):417-420

Wang W, Qiu Z, Tan H, Cao L (2014) Siderophore production by actinobacteria. BioMetals 27:623-631

Wardman P, Candeias LP (1996) Fenton chemistry: an introduction. Radiat Res 145(5):523-531

Wilkins RG (1991) Kinetics and mechanism of reactions of transition metal complexes, 2nd edn. $\mathrm{VCH}$, Weinheim

Yang J, Bremer PJ, Lamont IL, McQuillan AJ (2006) Infrared spectroscopic studies of siderophorerelated hydroxamic acid ligands adsorbed on titanium dioxide. Langmuir 22:10109-10117

Zeronian SH, Inglesby MK (1995) Bleaching of cellulose by hydrogen peroxide. Cellulose 2 (4):265-272

Złoch M, Thiem D, Gadzała-Kopciuch R, Hrynkiewicz K (2016) Synthesis of siderophores by plant-associated metallotolerant bacteria under exposure to Cd2+. Chemosphere 156:312-325 
Open Access This chapter is licensed under the terms of the Creative Commons Attribution 4.0 International License (http://creativecommons.org/licenses/by/4.0/), which permits use, sharing, adaptation, distribution and reproduction in any medium or format, as long as you give appropriate credit to the original author(s) and the source, provide a link to the Creative Commons license and indicate if changes were made.

The images or other third party material in this chapter are included in the chapter's Creative Commons license, unless indicated otherwise in a credit line to the material. If material is not included in the chapter's Creative Commons license and your intended use is not permitted by statutory regulation or exceeds the permitted use, you will need to obtain permission directly from the copyright holder. 